NBER WORKING PAPER SERIES

\title{
STOCHASTIC TAXATION AND ASSET PRICING IN DYNAMIC GENERAL EQUILIBRIUM
}

\author{
Clemens Sialm
}

Working Paper 9301

http://www.nber.org/papers/w9301

\author{
NATIONAL BUREAU OF ECONOMIC RESEARCH \\ 1050 Massachusetts Avenue \\ Cambridge, MA 02138 \\ October 2002
}

\begin{abstract}
I thank Doug Bernheim, Darrell Duffie, Bob Hall, Jim Hines, Ken Judd, Dirk Krueger, Davide Lombardo, Robert McMillan, Sita Nataraj, Monika Piazzesi, Jim Poterba, Antonio Rangel, Tom Sargent, John Shoven, Joel Slemrod, Kent Smetters, Jeff Strnad, Gerald Willmann, Shu Wu, and seminar participants at the Board of Governors of the Federal Reserve Bank, Harvard, Illinois, Michigan, the San Francisco Federal Reserve Bank, Stanford, UC Davis, UC San Diego, University of Southern California, Wellesley, and Williams for helpful comments on earlier drafts. All errors are mine. Financial support by the Kapnick Foundation and the Stanford Institute for Economic Policy Research is gratefully acknowledged. The views expressed herein are those of the authors and not necessarily those of the National Bureau of Economic Research.
\end{abstract}

(C) 2002 by Clemens Sialm. All rights reserved. Short sections of text, not to exceed two paragraphs, may be quoted without explicit permission provided that full credit, including (C) notice, is given to the source. 
Stochastic Taxation and Asset Pricing in Dynamic General Equilibrium

Clemens Sialm

NBER Working Paper No. 9301

October 2002

JEL No. G1, H2, E4

\begin{abstract}
$\underline{\text { ABSTRACT }}$
Tax rates have fluctuated considerably since federal income taxes were introduced in the United States in 1913. This paper analyzes the effects of stochastic taxation on asset prices in a dynamic general equilibrium model. Stochastic taxation affects the after-tax returns of both risky and safe assets. Whenever taxes change, bond and equity prices adjust to clear the asset markets. These price adjustments affect assets with long durations, such as equities and long-term bonds, more than short-term assets. Under plausible conditions, investors require higher term and equity premia as compensation for the risk introduced by tax changes.
\end{abstract}

Clemens Sialm

University of Michigan Business School

701 Tappan Street

Ann Arbor, MI 48105

and NBER

sialm@umich.edu 


\section{Introduction}

One of the few certain forecasts about the tax system is that it will change. Since federal income taxes were introduced in 1913, the tax system of the United States has been reformed several times. Marginal income tax rates have fluctuated considerably over this period, as depicted in Figure 1, which shows the federal marginal income tax rates for individuals in five different tax brackets. ${ }^{1}$ On top of marginal tax rate changes, other provisions of the tax code also changed, adding to the overall uncertainty of tax law. ${ }^{2}$ This paper investigates how stochastic tax policies affect asset prices and whether they introduce an additional risk factor in the economy, which changes equity and term premia.

The theoretical model generalizes the Lucas (1978) asset pricing model by introducing a flat consumption tax that follows a two-state Markov chain. Whenever taxes change, stock and bond prices adjust instantaneously to clear the asset markets. The price adjustments are more severe for assets with long durations, such as equities and long-term bonds, than for assets with shorter durations. Individuals require higher expected returns for holding the assets with more severe price changes under plausible conditions. Hence, long-term bonds and equities tend to pay on average higher returns than short-term bonds. The asset pricing implications are not driven by a differential taxation of different asset classes because a consumption tax affects bonds and stocks in a symmetric way.

Stochastic taxes have three effects on asset prices. First, they change the level of disposable income over time (income effect). Frequent tax changes increase the variability of consumption for a given production process. A higher variability of consumption significantly affects asset prices and leads to a higher equity premium, as previously shown in the asset pricing literature. Second, time-varying tax rates distort the relative price of consumption over time and affect the incentives to save and invest (substitution effect). Even if all the tax revenues are rebated to taxpayers and the consumption process remains completely unaffected by tax changes, stochastic taxes affect asset prices and equity and term premia. Third, taxes can influence the rate of

\footnotetext{
${ }^{1} \mathrm{~A}$ detailed description of the data is given in Appendix A.1.

${ }^{2}$ Pechman (1985) traces the changes in the effective distribution of tax burdens over the period from 1966 to 1985. Tax burdens increased in the lower part of the income scale, declined sharply at the top, and remained roughly the same or rose slightly in between. He shows that effective taxes varied less than marginal tax rates.
} 
Figure 1: Marginal Income Tax Rates at Different Real Income Levels The marginal income tax rates over the period from 1913 to 1999 are depicted for families with real income levels of 50, 100, 250, and 500 thousand U.S. dollars (with 1999 consumer prices), and the marginal tax rate for the highest tax bracket.

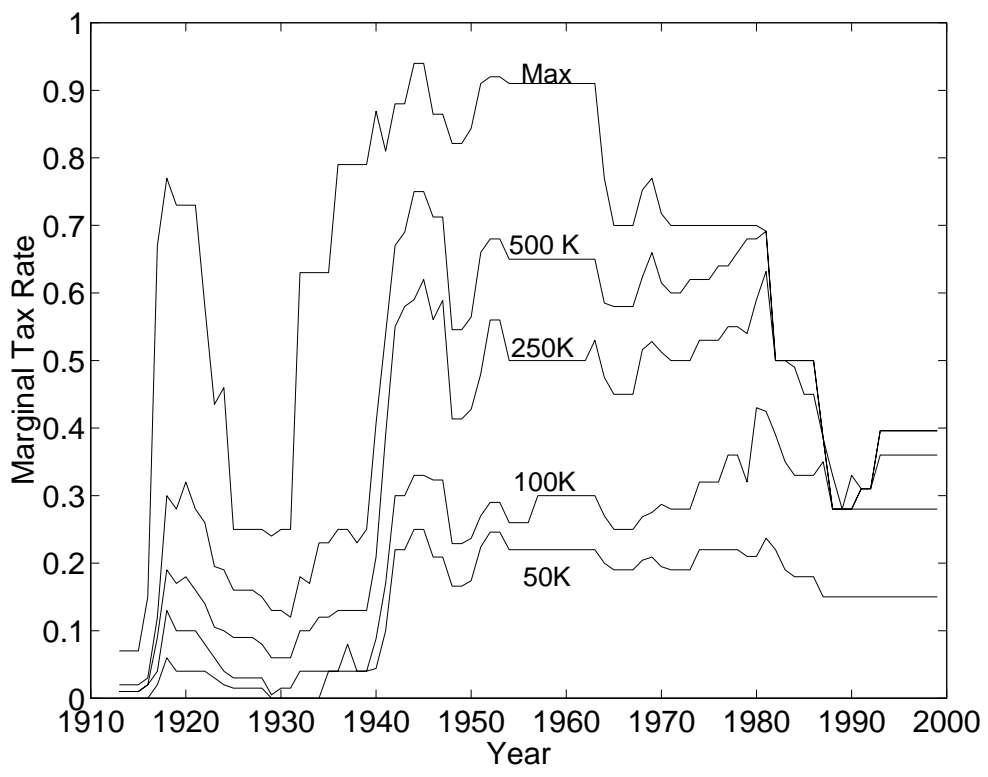

growth of the economy and thereby affect asset prices (growth effect). Some tax regimes might be more conducive to economic growth than others.

A numerical example illustrates that, for reasonable parameter values, stochastic taxation increases the return premium of long-term bonds and equities over short-term bonds, without generating implausible returns of short-term bonds. The effects of tax changes on the equity and term premia are significant even if all the tax revenues are rebated to the taxpayers.

This paper is related to the literature in finance that addresses the high equity premium and to the literature in public economics that analyzes the effects of taxes on saving decisions and portfolio choice. The papers in the finance literature show that conventional asset pricing models cannot generate equity premia as observed in the United States during the last century. The literature has focused on three related puzzles: Mehra and Prescott (1985) show that extremely high levels of risk aversion are necessary to explain the 
large equity premium (equity premium puzzle). ${ }^{3}$ Weil (1989) demonstrates that the risk-free rate increases dramatically at higher levels of risk aversion (risk-free rate puzzle). And Shiller (1981) argues that stock prices tend to be more volatile than the underlying uncertainty in the economy (excess volatility puzzle). This paper sheds some light on the effects of stochastic taxes on asset prices and equity and term premia. Many alternative explanations have been identified as potential explanations of these puzzles. ${ }^{4}$

The papers in public economics analyze the effects of taxes on saving decisions and portfolio choice. The effect of taxation on portfolio allocation in a partial equilibrium model was first discussed by Domar and Musgrave (1944) and Stiglitz (1969). ${ }^{5}$ A few papers discuss the effects of uncertain future taxes on the economy. Auerbach and Hines (1988) analyze the pattern of U.S. corporate investment incentives over the period between 1953 and 1986, incorporating the feature that investors are aware that next year's tax code may not be the same as this year's. Bizer and Judd (1989) present a dynamic general equilibrium model where taxpayers understand the uncertainty in tax policy when making their investment decisions. The impact of tax policy uncertainty on firm-level and aggregate investment is estimated by Hassett and Metcalf (1999). Several recent papers investigate the impact of specific tax reforms on asset returns. ${ }^{6}$ Sialm (2001) shows that tax reforms have an economically and statistically significant correlation with asset returns. The impact of tax changes on asset prices is more pronounced for assets with long durations, such as stocks and long-term bonds, than for assets with shorter durations.

\footnotetext{
${ }^{3}$ Hansen and Singleton (1983) and Hansen and Jagannathan (1991) provide an alternative illustration of the equity premium puzzle.

${ }^{4}$ Some proposed resolutions include more general preferences and expectations of individuals (e.g., Epstein and Zin (1989), Abel (1990), Constantinides (1990), and Campbell and Cochrane (1999)); incomplete markets (e.g., Mankiw (1986), Constantinides and Duffie (1996), Heaton and Lucas (1996), Storesletten, Telmer, and Yaron (2001), and Constantinides, Donaldson, and Mehra (2002)); trading and transaction costs (Mankiw and Zeldes (1991) and Vissing-Jørgensen (2002)); and rare events and survivorship bias (Rietz (1988) and Jorion and Goetzmann (1999)). Kocherlakota (1996) and Campbell (1999) are recent surveys of this literature.

${ }^{5}$ More recently, Eaton (1981), Gordon (1985), Judd (1985), Hamilton (1987), Kaplow (1994), and Zodrow (1995) analyze the effects of different tax systems on risk taking in more general models.

${ }^{6}$ See for example, Amoako-Adu, Rashid, and Stebbins (1992), Guenther and Willenborg (1999), Slemrod and Greimel (1999), Lang and Shackelford (2000), Blouin, Raedy, and Shackelford (2000), Sinai and Gyourko (2000), and McGrattan and Prescott (2001).
} 
This paper extends the literature in financial economics and the literature in public economics by analyzing the impact of frequent tax reforms on asset prices in a general equilibrium model. The effects of uncertain taxes on the distribution of asset prices and on term and equity premia have not been previously studied.

The remainder of the paper is divided into five sections. The next section describes a simple representative agent model. Section 3 derives closed form solutions for equity prices and illustrates the quantitative effect of stochastic taxes using a plausibly parameterized numerical example. The pricing of zero-coupon bonds with different maturities are explored in Section 4. Section 5 summarizes the necessary conditions for an increasing term structure of interest rates and Section 6 proves that the equity premium increases in an environment with tax reforms if certain conditions are satisfied. Section 7 checks the sensitivity of the results of the numerical model.

\section{The Model}

This paper generalizes the Lucas (1978) representative agent asset pricing model by introducing a flat consumption tax that follows a two-state Markov chain. This subsection describes the technology, the tax system, the preferences of the representative agent, and the equilibrium conditions.

\subsection{Technology}

The output in the exchange economy is exogenous and perishable. Aggregate output $y>0$ follows a geometric random walk with drift, where $z_{t}$ denotes its stochastic growth rate. Output growth $z_{t+1}$ has a mean of $\mu_{t}$ and a standard deviation of $\sigma_{t}$. The moments of the growth rate can be time-dependent. The distribution of the growth rate is known one period in advance.

$$
y_{t+1}=y_{t} \exp \left(z_{t+1}\right), \quad z_{t+1} \sim N\left(\mu_{t}, \sigma_{t}^{2}\right) .
$$

Two asset classes are traded in this economy: risk-free zero-coupon bonds with different maturities (B) and one risky equity security (S). A zero-coupon bond with remaining maturity $m \in\{0,1,2,3, \ldots\}$ pays a dividend of $d_{t}^{B, m}=$ 1 if $m=0$ and $d_{t}^{B, m}=0$ otherwise. Each individual can issue or buy these bonds. There is no net aggregate supply of any bonds. 
The equity security corresponds to the market portfolio and pays a dividend of $d_{t}^{S}=y_{t}$ at the beginning of each period $t .{ }^{7}$ The prices of the two asset classes $p_{t}^{S}$ and $p_{t}^{B, m}$ are defined 'ex-dividend.' The dividend and the price vectors at time $t$ are abbreviated with $d_{t} \in \Re_{+}^{n}$ and $p_{t} \in \Re_{+}^{n}$, where $n$ denotes the total number of assets traded in the economy $(n-1$ bonds and 1 equity security). Assets can be traded without incurring any transaction costs and investors face no borrowing or short-selling constraints.

\subsection{Tax System}

The government imposes a flat consumption tax and all assets face the same effective tax rates. ${ }^{8}$ Future tax rates $\tau$ are stochastic and follow a two-state Markov-Chain with $0 \leq \tau_{L} \leq \tau_{H}<1$. The transition probabilities $\phi_{i j}$ between the two states are defined as:

$$
\phi_{i j}=\operatorname{Prob}\left(\tau_{t+1}=\tau_{j} \mid \tau_{t}=\tau_{i}\right) .
$$

Time-varying tax rates may reflect unpredictable changes in the balance of power among different groups of taxpayers. The tax revenues are exactly identical to the outlays of the government. The government uses a fixed proportion $\omega \in[0,1]$ of the aggregate tax revenues $T_{t}$ to finance a public good $g_{t}=\omega T_{t}$ and rebates the remaining resources to the individuals as a lump-sum payment which can be used to purchase the aggregate consumption good without incurring any additional taxes.

The growth rate of the output and the dividends $z_{t+1}=\ln d_{t+1}^{S}-\ln d_{t}^{S}$ can depend on the current tax rate $\tau_{t}$ to allow for the possibility of distortionary

\footnotetext{
${ }^{7}$ This paper follows the equity premium literature by assuming that equity is a claim on the aggregate resources of the economy. In reality, stocks are a levered claim on the resources and exhibit considerably more risk. The return premium of an asset increases with its leverage (Modigliani and Miller 1958). Thus, this assumption understates the actual premium of levered assets.

${ }^{8}$ The goal of this paper is not to describe the detailed effects of all the specific features of the U.S. tax code on asset prices, it is to show how stochastic taxation affects asset prices and risk-premia. The current tax system in the United States is a progressive income tax where some sources of income are partially or completely tax-exempt or tax-deferred. In addition, states usually impose sales taxes on consumption goods. A flat consumption tax simplifies the algebra in this paper significantly and enables the derivation of closed form solutions. Bossaerts and Dammon (1994) derive testable restrictions on asset prices if investors have the option to time the realization of their capital gains and losses for tax purposes.
} 
taxes. The growth rate of dividends $z_{t+1}$ is independent of next period's tax rate $\tau_{t+1}$. This is a natural assumption because the future tax rate $\tau_{t+1}$ (which is announced at the beginning of period $t+1$ ) cannot affect the dividend $d_{t+1}^{S}$ (which accumulated during the period $t$ and is paid to shareholders at the beginning of period $t+1) .{ }^{9}$ The mean and the variance of the growth rate $z_{t+1}$ are $\mu_{L}$ and $\sigma_{L}^{2}$ if $\tau_{t}=\tau_{L}$ and $\mu_{H}$ and $\sigma_{H}^{2}$ if $\tau_{t}=\tau_{H}$.

\section{$2.3 \quad$ Utility}

The representative consumer purchases the $n$ available assets in quantities $x_{t} \in \Re^{n}$ to maximize expected life-time utility. Utility is time-separable and the period utility is separable in the private consumption good $c$ and the public good $g$. The coefficient $\omega$ is a measure of the separability between the private consumption good and the outlays of the government. If $\omega=0$ (no separability), then all the tax revenues are rebated to the taxpayers and the outlays of the government and the private consumption good are perfect substitutes. If $\omega=1$ (full separability), then all the tax revenues are used to finance the public good. The asset pricing results with full separability are identical to the case where the government throws away the tax revenues. The discount factor is denoted by $\beta \in(0,1)$. The period utilities of the two goods are denoted by $u(c)$ and $v(g)$, where $u^{\prime}(c)>0$ and $u^{\prime \prime}(c) \leq 0$.

The consumer's problem is to maximize:

$$
E_{t} \sum_{i=0}^{\infty} \beta^{i}\left(u\left(c_{t+i}\right)+v\left(g_{t+i}\right)\right),
$$

where:

$$
\begin{aligned}
& c_{t}=\left(1-\tau_{t}\right)\left[\left(p_{t}+d_{t}\right)^{\prime} x_{t-1}-p_{t}^{\prime} x_{t}\right]+(1-\omega) T_{t}, \\
& g_{t}=\omega T_{t} .
\end{aligned}
$$

Consumers are assumed to have a power-utility function with a coefficient of relative risk aversion $\alpha \in[0, \infty)$.

\footnotetext{
${ }^{9}$ An alternative assumption would be that the government pre-announces the tax rates one year in advance. This complicates the analysis by replacing the two states of the Markov chain with four states, because then the current tax regime depends not only on the current tax rate but also on the pre-announced future tax rate. The equity and the term premia in the base case are actually higher if the tax rates are pre-announced.
} 


$$
u\left(c_{t}\right)=\frac{c_{t}^{1-\alpha}-1}{1-\alpha} .
$$

Individuals with $\alpha=0$ are risk-neutral and individuals with $\alpha=1$ have logarithmic-preferences $u\left(c_{t}\right)=\ln \left(c_{t}\right)$. The risk aversion coefficient equals the reciprocal of the elasticity of intertemporal substitution.

The first-order conditions for the two asset classes are:

$$
\begin{aligned}
p_{t}^{B, m} u^{\prime}\left(c_{t}\right)\left(1-\tau_{t}\right) & =\beta^{m} E_{t}\left(u^{\prime}\left(c_{t+m}\right)\left(1-\tau_{t+m}\right)\right), \\
p_{t}^{S} u^{\prime}\left(c_{t}\right)\left(1-\tau_{t}\right) & =\beta E_{t}\left(u^{\prime}\left(c_{t+1}\right)\left(1-\tau_{t+1}\right)\left(p_{t+1}^{S}+d_{t+1}^{S}\right)\right) .
\end{aligned}
$$

An optimal solution to the agent's maximization problem must also satisfy the following transversality condition:

$$
\lim _{i \rightarrow \infty} \beta^{i} E_{t}\left(u^{\prime}\left(c_{t+i}\right)\left(1-\tau_{t+i}\right) p_{t+i}^{S} x_{t+i}^{S}\right)=0 .
$$

\subsection{Market Equilibrium}

For market equilibrium, the quantities of each asset demanded must equal the exogenous supply. The zero-coupon bonds have zero aggregate supply and the aggregate supply of equity is normalized to one. In equilibrium, the tax revenues, the consumption of the representative agent, and the provision of the publicly provided good amount to:

$$
\begin{aligned}
T_{t} & =\tau_{t} d_{t}^{S}, \\
c_{t} & =\left(1-\tau_{t}\right) d_{t}^{S}+(1-\omega) \tau_{t} d_{t}^{S}=\left(1-\omega \tau_{t}\right) d_{t}^{S}, \\
g_{t} & =\omega T_{t}=\omega \tau_{t} d_{t}^{S} .
\end{aligned}
$$

The (ex-post) marginal rate of intertemporal substitution of the private good is in equilibrium:

$$
\frac{u^{\prime}\left(c_{t+i}\right)}{u^{\prime}\left(c_{t}\right)}=\left(\frac{c_{t+i}}{c_{t}}\right)^{-\alpha}=\left(\frac{1-\omega \tau_{t+i}}{1-\omega \tau_{t}} \frac{d_{t+i}^{S}}{d_{t}^{S}}\right)^{-\alpha} .
$$

The first-order conditions (7) and (8) give the relationship determining the prices of bonds and equity securities. A zero-coupon bond with maturity $m \in\{0,1,2,3, \ldots\}$ and unit face value $d_{t}^{B, 0}=1$ should trade in equilibrium at the following price:

$$
p_{t}^{B, m}=\beta^{m} E_{t}\left(\frac{u^{\prime}\left(c_{t+m}\right)}{u^{\prime}\left(c_{t}\right)} \frac{1-\tau_{t+m}}{1-\tau_{t}}\right) .
$$


The price of the risky asset can be expressed in the following way if the transversality condition holds.

$$
\begin{aligned}
p_{t}^{S} & =\sum_{i=1}^{\infty} E_{t}\left(\beta^{i} \frac{u^{\prime}\left(c_{t+i}\right)}{u^{\prime}\left(c_{t}\right)} \frac{1-\tau_{t+i}}{1-\tau_{t}} d_{t+i}^{S}\right) \\
& =d_{t}^{S} \sum_{i=1}^{\infty} E_{t}\left(\beta^{i} \frac{1-\tau_{t+i}}{1-\tau_{t}}\left(\frac{1-\omega \tau_{t+i}}{1-\omega \tau_{t}}\right)^{-\alpha}\left(\frac{d_{t+i}^{S}}{d_{t}^{S}}\right)^{1-\alpha}\right)=d_{t}^{S} \delta_{t} .
\end{aligned}
$$

The current tax regime determines the probability distribution of future tax rates and of future growth rates $z_{t+i}=\ln d_{t+i}^{S}-\ln d_{t+i-1}^{S}$. The pricedividend ratio of equity $\delta_{t}$ and the price of the bond $p_{t}^{B, m}$ do therefore not depend on the level of the equity dividends $d_{t}^{S}$. They only depend on the current tax regime and the maturity of the bonds.

Taxes affect asset prices over three mechanisms. First, tax rates influence the consumption levels if some portion of the tax revenues are used to fund the public good (i.e., $\omega>0$ ). This affects the marginal rate of intertemporal substitution in equation (13). Tax changes result in a higher variability of consumption. Second, taxes distort the price of the private consumption good in different periods. Thus equations (14) and (15) include the ratio of the tax rates. Third, taxes influence the distribution of the growth rate of the economy.

A flat consumption tax has no effect on asset returns if the tax rate does not vary over time (i.e., $\tau_{L}=\tau_{H}$ ). The tax terms in the marginal rate of intertemporal substitution in equation (13) cancel if $\tau_{t}=\tau_{t+i}$ for $i \in\{0,1,2, \ldots\}$. The tax factors in the pricing equations (14) and (15) also cancel. In this case, taxes do not influence the distribution of the growth rate of the economy. A constant tax decreases consumption in all time periods by the same proportion and does not affect the marginal rate of intertemporal substitution if the utility function has a constant coefficient of relative risk aversion.

\section{Equity Valuation}

The first part of this section derives closed-form solutions of the equity prices in the two tax regimes. The second part solves the model for plausible parameter values and shows that the effects of tax regime changes are economically significant. 


\subsection{Analytical Derivation}

The price-dividend ratio of equity is denoted by $\delta_{t}=p_{t}^{S} / d_{t}^{S}$. The first-order condition (8) can be expressed as:

$$
\begin{aligned}
\delta_{t} & =\frac{p_{t}^{S}}{d_{t}^{S}}=\beta E_{t}\left[\frac{u^{\prime}\left(c_{t+1}\right)}{u^{\prime}\left(c_{t}\right)} \frac{1-\tau_{t+1}}{1-\tau_{t}} \frac{d_{t+1}^{S}}{d_{t}^{S}}\left(1+\delta_{t+1}\right)\right], \\
& =\beta E_{t}\left[\frac{d_{t+1}^{S}}{d_{t}^{S}}\right]^{1-\alpha} E_{t}\left[\frac{1-\tau_{t+1}}{1-\tau_{t}}\left(\frac{1-\omega \tau_{t+1}}{1-\omega \tau_{t}}\right)^{-\alpha}\left(1+\delta_{t+1}\right)\right] .
\end{aligned}
$$

The last equality follows from the independence of the dividend growth rate $z_{t+1}$ and the tax rate $\tau_{t+1}$ and the price-dividend ratio $\delta_{t+1}$. As seen in Section 2.4, the price-dividend ratio does only depend on the current tax regime. The growth rate of the dividend depends by assumption only on the tax rate at time $t$ and not on uncertain future tax rates. The first factor is determined by the dividend-process and is denoted by $\gamma_{t}=\beta E_{t}\left(d_{t+1}^{S} / d_{t}^{S}\right)^{1-\alpha}=$ $\beta \exp \left((1-\alpha) \mu_{t}+0.5(1-\alpha)^{2} \sigma_{t}^{2}\right)$. This factor depends on the current tax rate $\left(\gamma_{t}=\gamma_{L}\right.$ if $\tau_{t}=\tau_{L}$ and $\gamma_{t}=\gamma_{H}$ otherwise). The second factor is determined by the tax-process and depends on the future price-dividend ratio and current and future tax rates. I use the following abbreviation:

$$
\rho_{t, t+1}=\frac{1-\tau_{t+1}}{1-\tau_{t}}\left(\frac{1-\omega \tau_{t+1}}{1-\omega \tau_{t}}\right)^{-\alpha}>0 .
$$

The tax pricing factor $\rho_{t, t+1}$ equals one if the tax rates do not change $\left(\rho_{H H}=\rho_{L L}=1\right)$. It is defined as $\rho_{L H}$ if the tax rates increase and as $\rho_{H L}$ if they decrease. Note that $\rho_{L H}$ is the reciprocal of $\rho_{H L}$. The expected value of $\rho_{t, t+1}$ equals $\rho_{H}=\phi_{H H}+\phi_{H L} \rho_{H L}$ in the high- and $\rho_{L}=\phi_{L L}+\phi_{L H} \rho_{L H}$ in the low-tax regime. The price-dividend ratio depends only on the current tax regime and is denoted by $\delta_{t}=\delta_{H}$ if $\tau_{t}=\tau_{H}$ and $\delta_{t}=\delta_{L}$ otherwise.

$$
\begin{aligned}
\delta_{H} & =\gamma_{H}\left[\phi_{H H}\left(1+\delta_{H}\right)+\phi_{H L} \rho_{H L}\left(1+\delta_{L}\right)\right], \\
\delta_{L} & =\gamma_{L}\left[\phi_{L L}\left(1+\delta_{L}\right)+\phi_{L H} \rho_{L H}\left(1+\delta_{H}\right)\right] .
\end{aligned}
$$

Solving the system of linear equations for the two price-dividend ratios yields:

$$
\begin{aligned}
\delta_{H} & =\frac{\gamma_{H}\left[\rho_{H}+\gamma_{L}\left(1-\phi_{H H}-\phi_{L L}\right)\right]}{1-\left[\phi_{H H} \gamma_{H}+\phi_{L L} \gamma_{L}+\gamma_{H} \gamma_{L}\left(1-\phi_{H H}-\phi_{L L}\right)\right]} \\
\delta_{L}= & \frac{\gamma_{L}\left[\rho_{L}+\gamma_{H}\left(1-\phi_{H H}-\phi_{L L}\right)\right]}{1-\left[\phi_{H H} \gamma_{H}+\phi_{L L} \gamma_{L}+\gamma_{H} \gamma_{L}\left(1-\phi_{H H}-\phi_{L L}\right)\right]}
\end{aligned}
$$


To ensure that the transversality condition (9) holds, I assume that $0<$ $\gamma_{i}<1$ for $i \in\{L, H\}$. In this case, the price-dividend ratios in equations (20) and (21) are positive as shown in Appendix B.1.

The following proposition shows the relationship between the tax regime and the price-dividend ratio of equity securities in the special case where the dividend growth rate is independent of the current tax rate (part i) and in the general case (part ii).

Proposition 1 (i) If the tax and the dividend processes are independent (i.e., $\mu_{L}=\mu_{H}$ and $\sigma_{L}=\sigma_{H}$ ), then the price-dividend ratio is higher in the high-tax regime if $\alpha<\tilde{\alpha}$ and lower in the high-tax regime if $\alpha>\tilde{\alpha}$ :

$$
\delta_{H} \gtreqless \delta_{L} \quad \text { if } \quad \alpha \lesseqgtr \tilde{\alpha},
$$

where the critical risk aversion $\tilde{\alpha}$ is given by:

$$
\tilde{\alpha}=\frac{\ln \left(1-\tau_{L}\right)-\ln \left(1-\tau_{H}\right)}{\ln \left(1-\omega \tau_{L}\right)-\ln \left(1-\omega \tau_{H}\right)} .
$$

(ii) The price-dividend ratios in the two tax regimes have the following relationship with dependent dividend and tax processes:

$$
\delta_{H} \gtreqless \delta_{L} \quad \text { if } \quad \gamma_{H} \rho_{H} \gtreqless \gamma_{L} \rho_{L} .
$$

Proof: All proofs can be found in Appendix B.

If tax rates are not expected to change over time (i.e., $\tau_{H}=\tau_{L}$ ), then the price-dividend ratios are equal in the two states (i.e., $\delta_{H}=\delta_{L}=\gamma_{H} /(1-$ $\left.\left.\gamma_{H}\right)=\gamma_{L} /\left(1-\gamma_{L}\right)\right)$.

The coefficient $\tilde{\alpha}$ is larger than 1 and decreasing in $\omega . \tilde{\alpha}$ is defined for all $\omega \in(0,1]$. If all the tax revenues are rebated to the tax payers as a lump-sum distribution $(\omega=0)$, then $\tilde{\alpha}=\infty$. If the tax revenues are used to finance a separable public good $(\omega=1)$, then $\tilde{\alpha}=1$.

The special case where the dividend process does not depend on the current tax regime (part i) is discussed first. It is surprising that the price of equity can be higher in the high-tax regime. To better understand this result, it helps to analyze the different effects which determine asset prices. First, the government takes away a higher proportion of the aggregate dividends in high-tax regimes (income effect). Individuals would like to compensate for 
this tax by consuming more and by decreasing their demand of risky assets. In equilibrium, the supply of assets cannot adjust and the price of equity has to decrease due to the income effect. Second, consumption is relatively more expensive in periods with high taxes since future taxes are expected to be equal to or lower than current taxes (substitution effect). Individuals want to consume less and invest more during these periods. In equilibrium, the price of the risky asset has to increase as a consequence of this substitution effect. The elasticity of intertemporal substitution determines which of the two effects is more important. The second effect is stronger for individuals who are more willing to substitute consumption intertemporally (i.e., $\alpha<\tilde{\alpha}$ ), whereas the first effect is stronger for individuals with a low elasticity (i.e., $\alpha>\tilde{\alpha}$ ). The price-dividend ratios are identical in the two states if $\alpha=\tilde{\alpha}$. In this case, the two effects exactly offset each other because the expenditure elasticity equals zero.

If all the tax revenues are used to finance the separable public good (i.e., $\omega=1$ ), then $\tilde{\alpha}=1$ and equity valuations are higher in the high-tax regime only if individuals are less risk-averse than a log-utility individual. If all the tax revenues are rebated to the tax payers (i.e., $\omega=0$ ), then $\tilde{\alpha}=\infty$ and equities are always valued higher in the high-tax regime. In this case, the aggregate consumption level does not depend on the tax rate and is equal to the before-tax dividend. Thus, the first effect of taxes on equity valuation is completely eliminated with full redistribution. However, the second effect is still important, because individuals have an incentive to consume less in periods where the tax on consumption is higher. Valuations in the high-tax regime tend to be higher than those in the low-tax regime at low levels of risk aversion and at low levels of separability.

A dependence between the two processes adds a third effect of taxes on equity valuation. The current tax regime affects the distribution of future output levels (growth effect). It is difficult to characterize the condition for the general case, because the exponent of the pricing factor $\gamma$ is a quadratic function of the risk aversion $\alpha$.

The expected gross return of equity at time $t$ can be separated into the following two components because of the independence of the price-dividend ratio and the contemporaneous dividend:

$$
E_{t}\left(r_{t+1}\right)=E_{t}\left(\frac{p_{t+1}^{S}+d_{t+1}^{S}}{p_{t}^{S}}\right)=\xi_{t} E_{t}\left(\frac{1+\delta_{t+1}}{\delta_{t}}\right),
$$

where $\xi_{t}=E_{t}\left(d_{t+1}^{S} / d_{t}^{S}\right)=\exp \left(\mu_{t}+0.5 \sigma_{t}^{2}\right)$. 
Table 1: Numerical Assumptions

This table summarizes the base case parameter values used in the numerical example. $\alpha$ denotes the coefficient of relative risk aversion, $\beta$ the discount factor, $\tau_{L}$ and $\tau_{H}$ the tax rates in the low-tax and high-tax regimes, $\phi_{L L}$ and $\phi_{H H}$ the transition probabilities between the two regimes, and $\mu$ and $\sigma$ the mean and the standard deviation of the logarithm of the growth rate of dividends.

\begin{tabular}{lcccccccc}
\hline Coefficient & $\alpha$ & $\beta$ & $\tau_{L}$ & $\tau_{H}$ & $\phi_{L L}$ & $\phi_{H H}$ & $\mu$ & $\sigma$ \\
Value & 2.50 & 0.98 & 0.30 & 0.40 & 0.80 & 0.80 & 0.02 & 0.05 \\
\hline
\end{tabular}

\subsection{Numerical Example}

To determine whether stochastic taxation is economically significant the model is solved for plausible underlying parameter values. In this example, the two tax rates are assumed to be $\tau_{L}=0.3$ and $\tau_{H}=0.4$ and the transition probabilities are $\phi_{L L}=\phi_{H H}=0.8$. This implies an average duration of a tax regime of five years. The average tax rate equals 35 percent and has a standard deviation of 5 percent. These values correspond roughly to past tax changes of an investor in the $\$ 250,000$ tax bracket. For example, between 1940 and 1999, tax rates increased four times and decreased six times by more than five percent. The average increase equaled 11.06 percent and the average decrease equaled 8.22 percent. The distribution of average tax changes is similar for the longer period between 1914-1999. ${ }^{10}$

The growth rate of the economy has a mean of 2 percent and a standard deviation of 5 percent. These moments correspond roughly to the real percapita growth rate of GNP in the U.S. ${ }^{11}$ The distribution of the growth rate

\footnotetext{
${ }^{10}$ I concentrate on the tax rates of relatively wealthy individuals, because those individuals hold a significant portion of financial assets. Poterba (2000) shows that the top one percent of equity holders own 52.2 percent of household holdings of corporate stock according to the 1998 Survey of Consumer Finances.

${ }^{11}$ The data are taken from Sialm (2001). The real per-capita growth rate of GNP has a mean of 2.4 percent and a standard deviation of 4.5 percent between 1940-1999. The standard deviation is considerably larger during the whole sample between 1914-1999 (5.89 percent). This assumption differs from those in some papers in the equity premium literature, which use the moments of aggregate consumption to calibrate the economy. There are two reasons for this modification. First, I am interested in analyzing the effects of tax changes on asset returns. Simply looking at the moments of after-tax consumption does not provide any insights into the effects of tax changes on asset returns. Second,
} 
Figure 2: Price-Dividend Ratios of Equity

The dashed curves show the price-dividend ratios in an environment without tax rate changes and the solid curves show the price-dividend ratios in the low-tax and the high-tax regime in an environment with tax rate changes. Panel A corresponds to the case where all the tax revenues are rebated to the tax payers $(\omega=0)$ and Panel B depicts the case where the tax revenues are used to finance a separable public good $(\omega=1)$.

Panel A: $\omega=0$

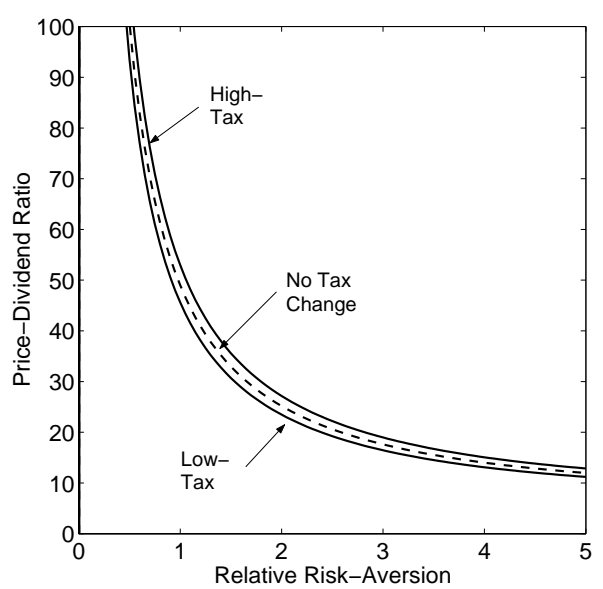

Panel B: $\omega=1$

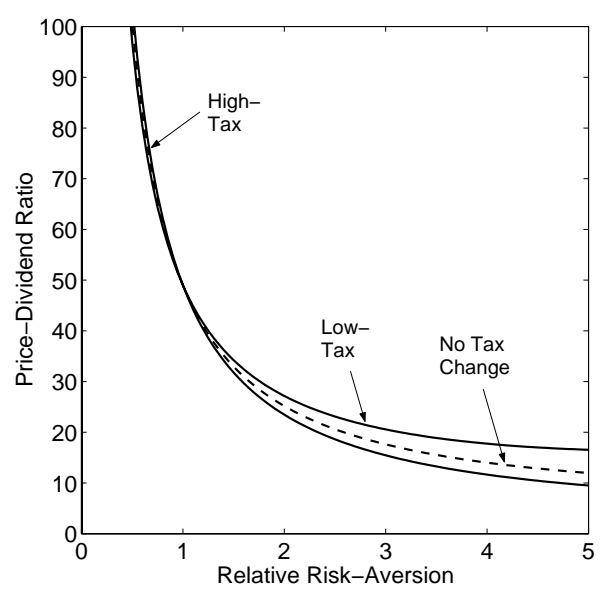

is assumed to be independent of the current tax regime. OLS regressions indicate that the per-capita growth rate does not depend significantly (at a five percent level) on the marginal tax rates. Sensitivity analyzes summarized in Section 7 show that changes in these assumptions do not affect the results much. The base case assumes a discount factor of $\beta=0.98$. The analyses in this section will concentrate on risk aversion coefficients in the range between 0 and 5. Table 1 summarizes all the assumptions in the base case.

Figure 2 shows how the price-dividend ratio depends on the coefficient of relative risk aversion. The two extreme cases with full lump-sum rebates ( $\omega=$

tax rate changes are much more significant for high-income individuals, who own a large proportion of the financial assets, than for the average individual. Using aggregated values of after-tax consumption ignores a large portion of the risk of changing tax rates, which is significant for individuals in relatively high marginal tax brackets. Vissing-Jørgensen (2002) discusses the biases of aggregating consumption levels. 
0 ) and with complete separability between the private and the public good $(\omega=1)$ are depicted in Panels A and B. The dashed curves show the pricedividend ratios in an environment without tax changes. The ratios depend neither on the tax rate nor on the separability coefficient $\omega$. Therefore, the dashed curves are identical in Panels $\mathrm{A}$ and $\mathrm{B}$. The price-dividend ratio without tax rate changes equals 20.61 at a risk aversion of $\alpha=2.5$. The ratio increases considerably as individuals become less risk-averse.

The two solid curves depict the price-dividend ratios in the low-tax and the high-tax regime in an environment with tax rate changes. The valuation is always higher in the high-tax regime if all the revenues are rebated $(\omega=0)$. If all the tax revenues are used to finance the separable public good $(\omega=1)$, then the valuations are higher in the high-tax regime at low-levels of risk aversion (i.e., $\alpha<\tilde{\alpha}(\omega=1)=1$ ) and higher in the low-tax regime at highlevels of risk aversion. The valuations are exactly identical if individuals have logarithmic utility. In this case, tax regime changes have no effect on asset valuations, and the price-dividend ratio is exactly what it would be in an environment without tax changes.

If all the tax revenues are rebated as a lump-sum distribution to the representative agent (i.e., $\omega=0$ ), then with a risk aversion of 2.5 the pricedividend ratio equals 22.21 in the high-tax state and 19.23 in the low-tax state. Tax changes result in very large variations in stock prices. Stock prices increase instantaneously by 15.50 percent $(=22.21 / 19.23-1)$ whenever tax rates are raised and fall by 13.42 percent $(=19.23 / 22.21-1)$ whenever they decrease. If the tax revenues are used to finance a separable public good (i.e., $\omega=1$ ), then the price-dividend ratio equals 18.62 in the high-tax state and 23.11 in the low-tax state. Stock prices fall in this case by 19.43 percent whenever taxes increase and increase by 24.11 percent whenever taxes decrease. The model assumes that the timing of tax regime changes is not anticipated by the investors. In reality, market participants learn gradually about possible future tax reforms and the price changes occur over longer time horizons as investors adjust their expectations about future tax changes.

Figure 3 depicts the expected returns of equity in an environment with and without tax rate changes. Introducing tax regime changes increases the expected return of equity. The mean return of equity increases slightly from 7.11 percent to $7.32(7.58)$ percent if $\omega=0(\omega=1)$. The expected returns of the assets vary considerably between the different tax regimes. For example, the expected equity return is 4.00 (12.57) percent in the hightax regime and $10.63(2.59)$ percent in the low-tax regime if $\omega=0(\omega=1)$ 
Figure 3: Expected Returns of Equity

Panels $\mathrm{A}$ and $\mathrm{B}$ show the expected returns of equity in the case where all the tax revenues are rebated to the tax payers $(\omega=0)$ and where the tax revenues are used to finance a separable public good $(\omega=1)$. The dashed curves show the expected returns in an environment without tax rate changes and the solid curves show the expected returns with tax rate changes.

Panel A: $\omega=0$

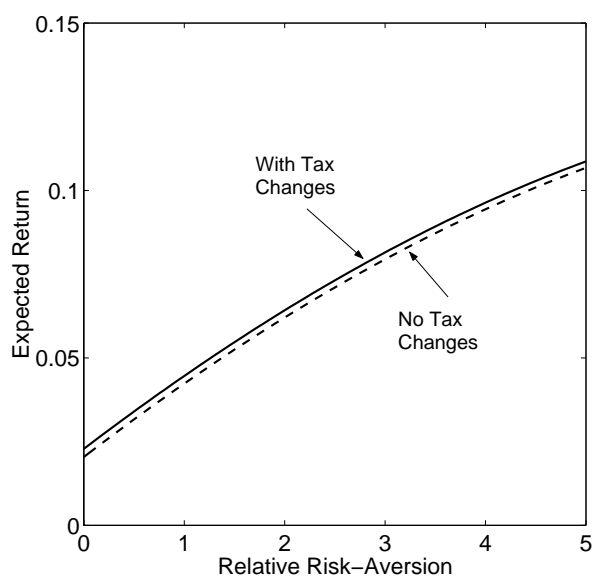

Panel B: $\omega=1$

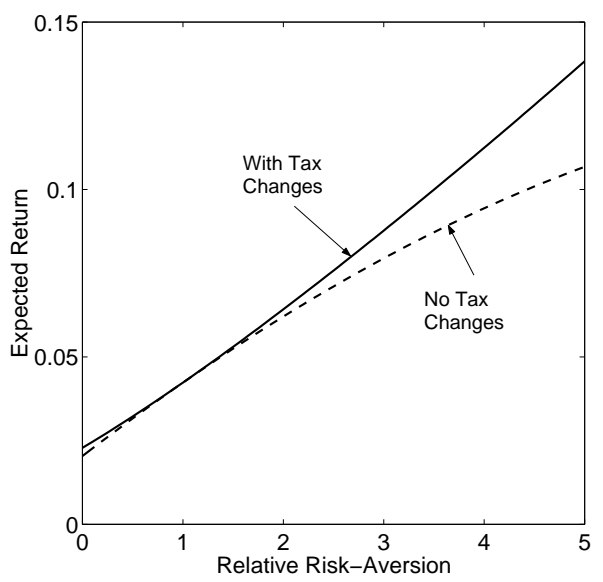

under the base case assumptions. This model of tax regime switches gives a plausible explanation for time-varying expected returns of assets as suggested by Campbell (1991). Expected returns tend to be higher in the high-tax regime if individuals are relatively risk averse and if a smaller share of the tax revenues is rebated to the taxpayers.

\section{Bond Valuation}

The prices of zero-coupon bonds can be derived from equation (7):

$$
p_{t}^{B, m}=\beta^{m} E_{t}\left[\frac{u^{\prime}\left(c_{t+m}\right)}{u^{\prime}\left(c_{t}\right)} \frac{1-\tau_{t+m}}{1-\tau_{t}}\right]=\lambda_{t} E_{t}\left[\rho_{t, t+1}\left(p_{t+1}^{B, m-1}+d_{t+1}^{B, m-1}\right)\right] .
$$

The second equality uses the definition $\lambda_{t}=\beta E_{t}\left(d_{t+1}^{S} / d_{t}^{S}\right)^{-\alpha}$. The separation into two components is possible because the price of the bond $p_{t}^{B, m}$ does not depend on the level of the dividend $d_{t}^{S}$. 
The equilibrium prices of a zero-coupon bond with maturity $m$ can be expressed recursively using the initial conditions $p_{H}^{B, 0}=p_{L}^{B, 0}=0$ and $d_{H}^{B, 0}=$ $d_{L}^{B, 0}=1$. Note that $d_{t}^{B, m}=0$ if $m \in\{1,2,3, \ldots\}$.

$$
\begin{aligned}
p_{H}^{B, m+1} & =\lambda_{H}\left[\phi_{H H}\left(p_{H}^{B, m}+d^{B, m}\right)+\phi_{H L} \rho_{H L}\left(p_{L}^{B, m}+d^{B, m}\right)\right], \\
p_{L}^{B, m+1} & =\lambda_{L}\left[\phi_{L L}\left(p_{L}^{B, m}+d^{B, m}\right)+\phi_{L H} \rho_{L H}\left(p_{H}^{B, m}+d^{B, m}\right)\right] .
\end{aligned}
$$

The next proposition proves in which tax regime the valuations of zerocoupon bonds with a maturity of $m$ are higher.

Proposition 2 (i) Suppose that the dividend process is independent of the tax process. The price of a zero-coupon bond with a maturity of $m$ years is higher in the high-tax regime if $\alpha<\tilde{\alpha}$ and lower in the high-tax regime if $\alpha>\tilde{\alpha}$ :

$$
p_{H}^{B, m} \gtreqless p_{L}^{B, m} \quad \text { if } \quad \alpha \lesseqgtr \tilde{\alpha} .
$$

(ii) Bond prices with a maturity of $m$ years have the following relationship with dependent dividend and tax processes:

$$
p_{H}^{B, m} \gtreqless p_{L}^{B, m} \quad \text { if } \quad \lambda_{H} \rho_{H} \gtreqless \lambda_{L} \rho_{L} .
$$

If the dividend growth rate does not depend on the current tax rate (part i), then the condition for bond prices is exactly identical to the condition for equity securities from Proposition 1. In this case, valuations of both assets are higher in the high-tax regime if $\alpha<\tilde{\alpha}$. The income and the substitution effects have the same intuition for bonds as for equity securities.

The growth effect, which is relevant if the dividend and the tax processes are dependent, differs for equity and one-period zero-bonds. The growth rate affects the discount factor of bonds $\lambda$ but not the future payoffs of the bonds. For equity, both the discount factor $\gamma$ and the future dividends are affected. This explains why the condition (ii) for bonds differs in general from the condition for equity.

The properties of bond prices are discussed in more detail in Appendix B.3. If tax regimes are persistent $\left(\phi_{H H}+\phi_{L L}>1\right)$, then the ratio of the bond prices in the two tax regimes converges monotonically towards a steady state value as the maturity of the bonds increases. If tax regimes are transitory $\left(\phi_{H H}+\phi_{L L}<1\right)$, then the ratio of the two bond prices oscillates around the steady-state level and converges if either $\phi_{H H}>0$ or $\phi_{L L}>0$. If the tax rate 
Figure 4: Expected Returns of Short-Term Bonds

Panels A and B show the expected returns of a zero-coupon bond with a maturity of one year. The dashed curves show the expected returns in an environment without tax rate changes and the solid curves show the expected returns with tax rate changes.

Panel A: $\omega=0$

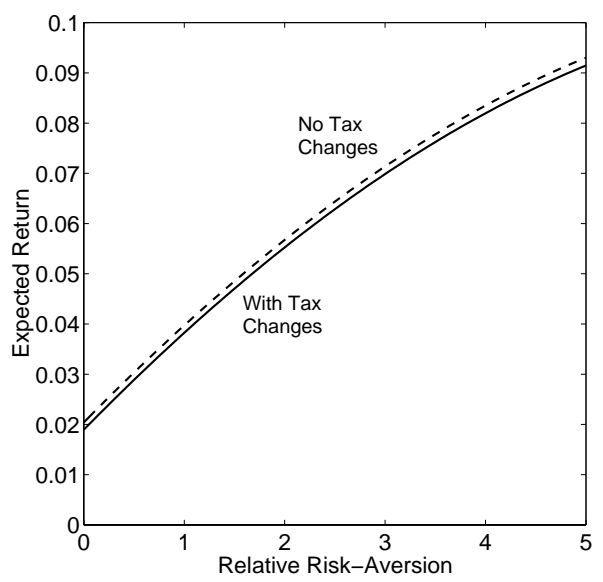

Panel B: $\omega=1$

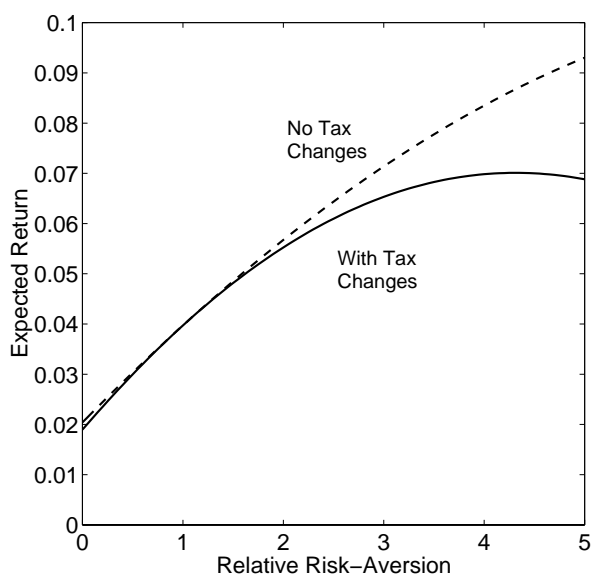

switches deterministically between the two regimes $\left(\phi_{H H}=\phi_{L L}=0\right)$, then the ratio of the bond prices fluctuates between two different values and does not converge.

Figure 4 depicts the expected returns of a one-period zero-coupon bond in an environment with and without tax rate changes using the base case assumptions from Table 1. If tax rates do not change over time, then the return of the short-term bond equals 6.44 percent at a risk aversion of $\alpha=2.5$ and increases significantly at higher levels of risk aversion. This result is at odds with the average historical real return of short-term Treasury securities. Introducing tax changes decreases the expected return of short-term bonds slightly. At a risk aversion of $\alpha=2.5$, the mean return of the risk-free one-period bond equals 6.29 (6.10) percent if $\omega=0(\omega=1)$. 


\section{$5 \quad$ Term Structure of Interest Rates}

In an environment without tax changes, the expected gross return of a bond with maturity $m$ is given by:

$$
E\left(r^{B, m}\right)=\frac{p^{B, m-1}}{p^{B, m}}=\frac{p^{B, m-1}}{\lambda p^{B, m-1}}=\frac{1}{\lambda} .
$$

Corollary 1 The expected return of zero-coupon bonds does not depend on the maturity $m$ if tax rates do not vary over time.

Next, I discuss the term structure in an environment with tax rate changes. The expected gross returns of a bond with maturity $m$ in the two tax regimes is given by:

$$
\begin{aligned}
& E\left(r_{H}^{B, m}\right)=\frac{\phi_{H H} p_{H}^{B, m-1}+\phi_{H L} p_{L}^{B, m-1}}{p_{H}^{B, m}}, \\
& E\left(r_{L}^{B, m}\right)=\frac{\phi_{L L} p_{L}^{B, m-1}+\phi_{L H} p_{H}^{B, m-1}}{p_{L}^{B, m}} .
\end{aligned}
$$

The next proposition summarizes the necessary conditions for an increasing or decreasing term structure of interest rates.

Proposition 3 Suppose that tax regimes are persistent $\left(\phi_{H H}+\phi_{L L}>1\right)$.

(i) Longer term bonds have a higher expected return than shorter term bonds if the dividend process is independent of the tax process.

(ii) The slope of the term structure of interest rates is determined by the following condition with dependent dividend and tax processes:

$$
E\left(r_{i}^{B, m+1}\right) \gtreqless E\left(r_{i}^{B, m}\right) \text { for } i \in\{L, H\} \text { if }\left(\lambda_{L} \rho_{L}-\lambda_{H} \rho_{H}\right)\left(1-\rho_{H}\right) \gtreqless 0 \text {. }
$$

A necessary condition for a monotonously increasing term structure is that tax regimes are persistent (i.e., $\phi_{H H}+\phi_{L L}>1$ ). This condition is plausible because tax rates are more likely to remain unchanged than to change in each period. I will demonstrate that the term structure is nonmonotonous if tax regimes are only transitory.

Part (i) states that the term premium increases with the maturity of the bonds if the distribution of dividends does not depend on the current tax rate $\left(\lambda_{H}=\lambda_{L}\right)$. Stochastic taxes add an additional source of uncertainty to the 
Figure 5: Expected Bond Returns

The dashed curves show the expected bond returns in an environment without tax rate changes and the solid curves show that the expected bond returns increase as the maturity of zero-coupon bonds increases. Panel A corresponds to the case where all the tax revenues are rebated to the tax payers $(\omega=0)$ and Panel B depicts the case where the tax revenues are used to finance a separable public good $(\omega=1)$.
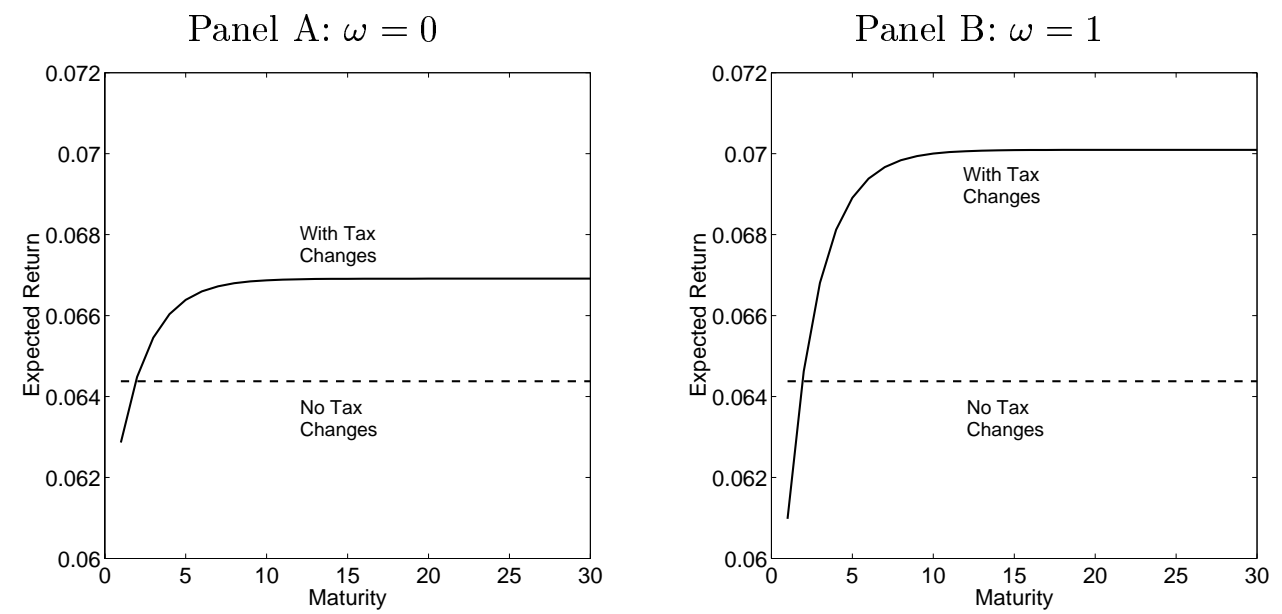

economy and require higher returns to long-duration bonds that are exposed more to tax uncertainty. This result does not depend on the uses of the tax revenues. The numerical example below shows that the term structure is usually steeper when the tax revenues are not rebated $(\omega=1)$. In this case, tax changes affect both the consumption levels of the representative individual and the relative price of consumption over time. If the tax revenues are completely rebated $(\omega=0)$, then the consumption levels are unaffected by tax changes. However, bond prices are still affected by tax changes because the relative price of consumption varies over time.

Part (ii) allows the growth rate of the economy to be correlated with the current tax regime. A decreasing term structure is possible if the distribution of the dividend growth rate is sufficiently different between the two tax regimes. The term structure is decreasing if the tax changes are such that they reduce the aggregate uncertainty investors are exposed to. 
The expected returns oscillate around the long-term values if tax regimes are transitory $\left(\phi_{H H}+\phi_{L L}<1\right)$. In this case, the expected returns are not monotonous in the maturity. If tax regimes switch deterministically $\left(\phi_{H H}=\phi_{L L}=0\right)$, then expected returns of bonds with different maturities fluctuate between only two values and do not converge. Section B.4 in the Appendix describes the properties of bond returns in more detail.

Next, I compute the expected bond returns for different maturities given the parametric assumptions from Table 1. Figure 5 depicts the expected bond returns with (solid curves) and without (dashed curves) tax rate changes. In an environment without tax changes, the term structure of interest rates is flat with a yield of 6.44 percent with the parameters given in Table 1 . With tax regime shifts, the expected returns of zero-coupon bonds increase with the maturity. All the bonds with a maturity of more than one year are higher in a model with stochastic taxes than the bond returns without tax changes. The expected returns of the bonds converge to 6.69 (7.01) percent with $\omega=0$ $(\omega=1)$ as $m \rightarrow \infty$. The average term premium amounts to 0.89 percent $(=7.01-6.10)$ if $\omega=1$ and 0.40 percent $(=6.69-6.29)$ if $\omega=0$.

\section{Equity Premium}

The equity premium compares the expected return of equity to the return of risk-free one-period zero-coupon bonds. The following proposition states the conditions under which the equity premium increases in an environment with tax changes.

Proposition 4 The equity premium $\pi_{i}$ for $i \in\{L, H\}$ equals the sum of a premium due to dividend uncertainty $\pi_{i}^{D}$ and a premium due to tax changes $\pi_{i}^{T}:$

$$
\pi_{i}=E_{t}\left(r_{t+1}^{S}\right)-r_{t}^{B, 1}=\pi_{i}^{D}+\pi_{i}^{T} .
$$

(i) If the dividend process is independent of the tax process, then both premia are positive.

(ii) The sign of the tax premium is determined by the following condition with dependent tax and dividend processes:

$$
\pi_{i}^{T} \gtreqless 0 \text { for } i \in\{L, H\} \text { if }\left(\gamma_{L} \rho_{L}-\gamma_{H} \rho_{H}\right)\left(1-\rho_{H}\right) \gtreqless 0 .
$$

The excess return of stocks over short-term bonds is due to two premia. The first premium $\pi_{i}^{D}$ equals the equity premium in an environment without 
tax changes and is always positive. The second premium $\pi_{i}^{T}$ is due to tax changes and is positive if the condition in part (ii) is satisfied. It is possible that the equity premium becomes negative if the distribution of the dividend growth rate is sufficiently different between the two tax regimes. The equity premium decreases if the tax changes are such that they reduce the aggregate uncertainty investors are exposed to. Part (i) states that the tax premium is always positive if the distribution of dividends does not depend on the current tax rate. The sign of the tax premium does not depend on whether tax regimes are transitory or persistent.

The conditions in parts (ii) of Propositions 3 and 4 look very similarly, but they depend on $\lambda$ and $\gamma$, respectively. These two factors differ, because the growth rate of dividends affects only the payoffs of equity and not the payoffs of bonds. It is therefore possible to observe an increasing term structure of interest rates and a negative tax premium. If the growth rate is independent of the tax rate, then the equity and the term premium increase after introducing tax reforms.

The three effects that drive the asset valuation give an intuition of the effect of tax changes on the equity premium. The first effect (income effect) increases the equity premium because tax changes increase the variability of consumption over time. It is well-known that an increase in consumption volatility increases the required risk-premia. The first effect disappears if all the tax revenues are rebated to the representative agent. In this case, the consumption process is not affected by tax changes. The second effect (substitution effect) remains important in the case with a full rebate. Varying tax rates affect the relative price of consumption over time. The third effect (growth effect) can increase or decrease the equity premium, depending on the correlation between taxes and productivity growth. Individuals require higher expected returns for holding long-duration assets, such as stocks and long-term bonds, compared to short-term bonds. The increase of the equity premium occurs because equities have a relatively long duration. ${ }^{12}$

The following figures compute the equity premium using the parameters in Table 1. The dashed curves of Figure 6 show that the equity premium increases slowly with risk aversion in a conventional model without tax changes. For example, the equity premium equals only 0.67 percent at a coefficient of risk aversion of $\alpha=2.5$. This is considerably lower than the equity premium of between 2.55 and 4.32 percent estimated by Fama and French (2002). Fig-

\footnotetext{
${ }^{12}$ Abel (1999) divides the equity premium into a term premium and a risk premium.
} 
Figure 6: Equity Premium

The dashed curves show the equity premia without tax rate changes and the solid curves show the premia with tax rate changes. Panel A corresponds to the case where all the tax revenues are rebated to the tax payers $(\omega=0)$ and Panel B depicts the case where the tax revenues are used to finance a separable public good $(\omega=1)$.

Panel A: $\omega=0$

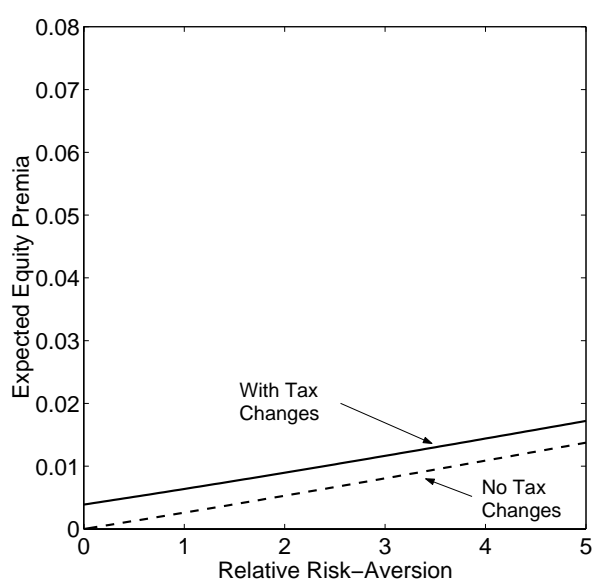

Panel B: $\omega=1$

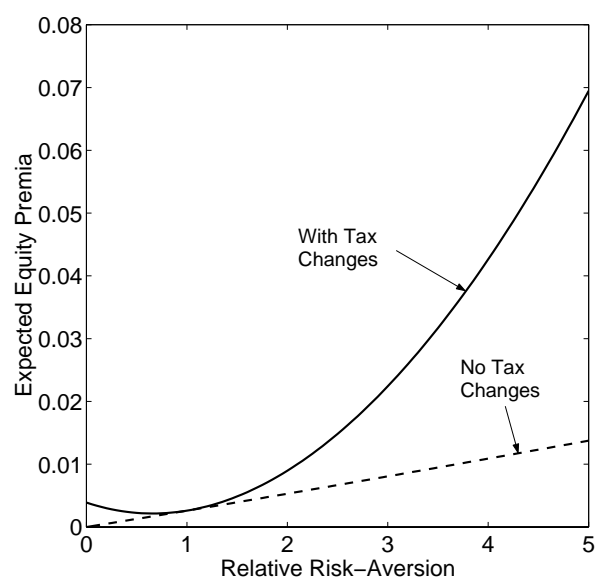

ure 6 demonstrates that the equity premium is larger in a model with tax rate changes (solid curves). Panel $\mathrm{B}$ shows that the equity premium is highly sensitive to changes in the coefficient of relative risk aversion if the government does not rebate the tax revenues to the taxpayers (i.e., $\omega=1$ ). The equity premium is lowest at a risk aversion of $\alpha=0.66$. An average equity premium of 6.95 percent results at a coefficient of relative risk aversion of 5 . The equity premium at this level of risk aversion without tax rate changes would have been only 1.37 percent.

Panel A of Figure 6 shows the equity premium if the government rebates all the tax revenues to the representative individual (i.e., $\omega=0$ ). The equity premium is higher in this case compared to the case where $\omega=1$ if the risk aversion is smaller than $\alpha=2.0$. It is still considerably higher than the equity premium without tax regime changes. However, the equity premium increases only slowly with risk aversion. In this paper, equity securities are unlevered, because their payoffs correspond to the total production of the 
economy. The equity premia of levered securities increase with the leverage. This additional factor together with the additional modifications of conventional asset pricing models mentioned in the introduction helps to match the historical moments of equity returns.

The higher term premium accounts for a large portion of the equity premium. The effect of tax rate changes on assets depends primarily on the duration of the assets. Both equity and bonds have long durations and are highly sensitive to changes in tax rates. For tax changes to have a substantial effect on the equity premium, risk-aversion has to be sufficiently large and separability between the public and the private good has to be sufficiently high.

\section{Sensitivity Analyses}

To check the robustness of the numerical example in the previous section, the numerical assumptions are changed. Panels A and B of Figure 7 depict the expected returns of short- (one year) and long-term (thirty years) bonds and equity at different levels of persistence of the tax regimes with a symmetric transition matrix (i.e., $\phi_{H H}=\phi_{L L}$ ) and at a risk aversion of $\alpha=2.5$. If tax rates are permanent $\left(\phi_{H H}=\phi_{L L}=1\right)$, then the term premium due to tax changes equals zero. The equity premium equals the premium in an environment without tax changes. The price changes are large and infrequent at high persistence levels and small and frequent at low persistence levels. The term premium is largest for intermediate persistence levels, when tax changes are common and price changes are relatively large. The term premium tends to be maximized if $\phi_{H H}=\phi_{L L}=0.5$, because then the uncertainty about future tax rates is highest. The level of the term premium is lower if all the tax revenues are rebated to the tax payers.

Panels $\mathrm{C}$ and D of Figure 7 show the dependence of the returns of the two assets on the difference between the tax rates in the two states. The average tax rate is kept constant at its average level of 35 percent. As the difference between the tax rates in the two tax regimes increases, the mean return of equity securities and long-term bonds increases and the mean return of short-term bonds decreases. Most of the equity premium is due to the term premium if the tax difference is relatively large.

The numerical exercises performed previously assume that the distribution of the growth rates is identical in the two tax regimes. The results in 
Figure 7: Asset Returns with Changing Persistence Levels and Tax Rates The expected returns of one and thirty-years zero-coupon bonds and equity securities are depicted at different persistence levels (Panels A and B) and with different tax rates (Panels $\mathrm{C}$ and $\mathrm{D}$ ).

Panel A: $\omega=0$

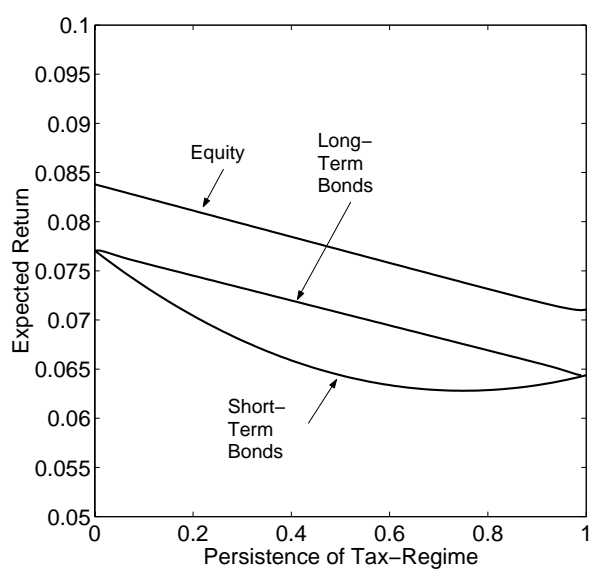

Panel C: $\omega=0$

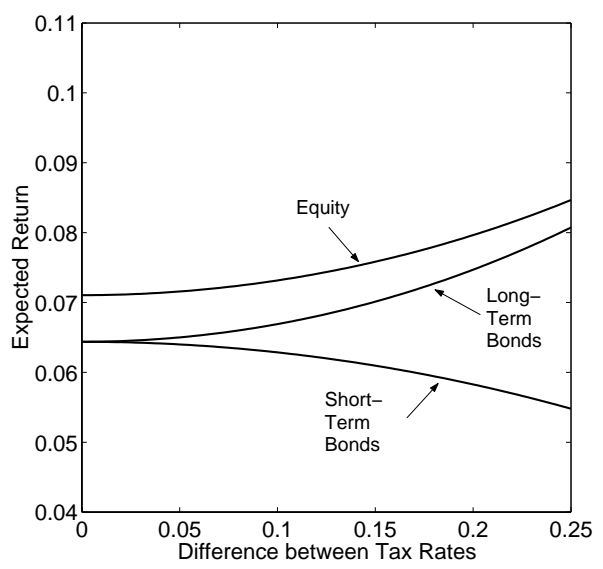

Panel B: $\omega=1$

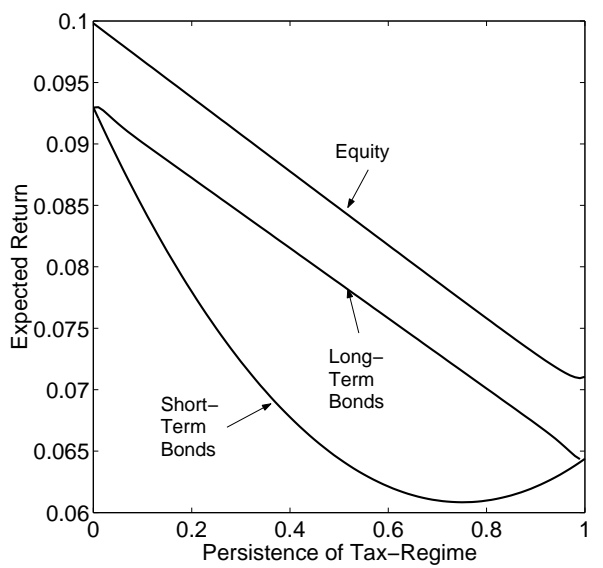

Panel D: $\omega=1$

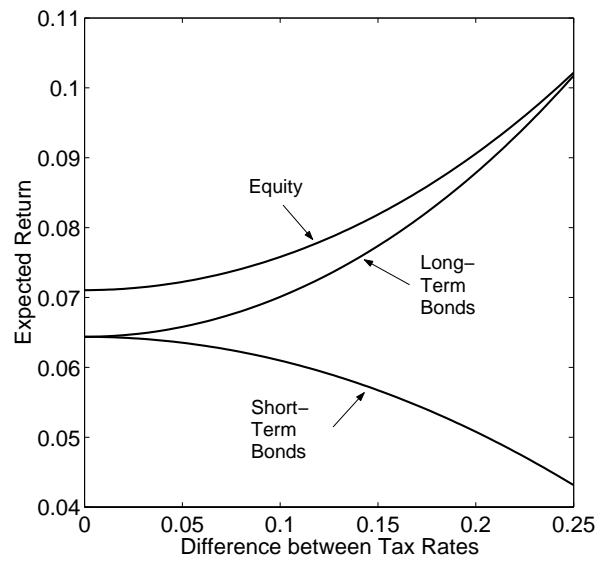


Section 6 demonstrate that the premium due to tax changes can be either positive or negative if the growth rate of the economy depends on the tax rate. The differences between the moments of the growth rates in the two regimes have to be relatively large to generate a negative tax premium. If $\sigma_{H}=\sigma_{L}$, then the growth differential $\mu_{H}-\mu_{L}$ would need to be larger than 4.1 percent for $\omega=0$ and the differential $\mu_{H}-\mu_{L}$ would need to be smaller than -6.2 percent for $\omega=1$ to generate a negative tax premium.

The previous results assume that tax rates follow a two-state Markov chain. The results do not change much if additional states are introduced. Alternative specifications of the Markov chain can either increase or decrease the equity premium relative to the base case with two states. For example, a three-state Markov chain with $\tau \in\{0.275,0.350,0.425\}$ and with a probability of remaining in the current state of 0.8222 and equal probabilities to switch to any of the two other states has the same unconditional mean and variance of the tax rates and the same expected tax change in each period as the two-state Markov chain used previously. In this example, the equity premium increases marginally from 1.03 to 1.04 percent if $\omega=0$ and it increases from 1.48 to 1.51 percent if $\omega=1$. The equity premium increases slightly because larger tax changes become possible. The equity premia are considerably larger in the highest and the lowest tax state compared to the middle tax state.

\section{Conclusions}

This paper generalizes the Lucas (1978) asset pricing model by introducing a flat consumption tax, which follows a two-state Markov chain. This tax does not merely affect equity securities, it affects all assets symmetrically. Whenever taxes change, asset prices need to adjust instantaneously to clear asset markets. These price changes increase the variability of expected and actual asset returns. The price adjustments are more severe for assets with long durations, such as equity and long-term bonds, than for assets with shorter durations. Individuals require higher expected returns for holding the assets with more severe price changes under plausible conditions.

Tax rate changes affect asset prices even if all the tax revenues are rebated to the representative individual and the consumption process remains completely unaffected by tax changes. This occurs because tax changes distort the price of consumption over time and affect investment incentives. 
A numerical example demonstrates that stochastic taxation can account for a large portion of the return premium of equities over short-term bonds, without generating implausible returns on short-term bonds.

This paper makes several simplifications which could be relaxed in future work. First, the model uses a simple exchange economy without real investment opportunities to illustrate the effects of tax changes. Endogenizing real investment choices will result in a more realistic model of the economy. Second, the current tax system in the United States is not a flat consumption tax system. It is a progressive income tax system where some income sources are exempt from taxes (e.g., tax-deferred accounts, municipal bonds). In particular, stocks and bonds face different effective tax rates. The effects of tax reforms will differ if the effective tax on stock returns is smaller than the tax on bond returns and if the variability of the tax rates of the two assets differs. The analysis under a more realistic tax system would be interesting. Third, the tax shocks in this paper are exogenous. Time-varying tax rates may reflect unpredictable changes in the balance of power among different groups of taxpayers. A political-economy model could explain the mechanism that generates frequent tax rate changes. 


\section{References}

Abel, A. B. (1990). Asset Prices Under Habit Formation and Catching Up With the Joneses. The American Economic Review 80(2), 38-42.

Abel, A. B. (1999). Risk Premia and Term Premia in General Equilibrium. Journal of Monetary Economics 43(1), 3-33.

Amoako-Adu, B., M. Rashid, and M. Stebbins (1992). Capital Gains Tax and Equity Values: Empirical Test of Stock Price Reaction to the Introduction of Capital Gains Tax Exemption. Journal of Banking and Finance 16(2), 275-287.

Auerbach, A. J. and J. R. Hines (1988). Investment Tax Incentives and Frequent Tax Reforms. The American Economic Review 78(2), 211216.

Bizer, D. S. and K. L. Judd (1989). Taxation and Uncertainty. The American Economic Review 79(2), 331-336.

Blouin, J. L., J. S. Raedy, and D. A. Shackelford (2000). Capital Gains Holding Periods and Equity Trading: Evidence from the 1998 Act. NBER Working Paper 7827.

Bossaerts, P. and R. M. Dammon (1994). Tax-Induced Intertemporal Restrictions on Security Returns. Journal of Finance 49(4), 1347-1371.

Campbell, J. Y. (1991). A Variance Decomposition for Stock Returns. Economic Journal 101 (405), 157-179.

Campbell, J. Y. (1999). Asset Prices, Consumption, and the Business Cycle. In J. Taylor and M. Woodford (Eds.), Handbook of Macroeconomics, Vol. 1, Chapter 19, pp. 1231-1303. Amsterdam: NorthHolland.

Campbell, J. Y. and J. H. Cochrane (1999). By Force of Habit: A Consumption-Based Explanation of Aggregate Stock Market Behavior. Journal of Political Economy 107(2), 205-251.

Constantinides, G. M. (1990). Habit Formation: A Resolution of the Equity Premium Puzzle. Journal of Political Economy 98(3), 519-543.

Constantinides, G. M., J. B. Donaldson, and R. Mehra (2002). Junior Can't Borrow: A New Perspective on the Equity Premium Puzzle. Quarterly Journal of Economics 117(1), 269-296. 
Constantinides, G. M. and D. Duffie (1996). Asset Pricing with Heterogeneous Consumers. Journal of Political Economy 104 (2), 219-240.

Domar, E. D. and R. A. Musgrave (1944). Proportional Income Taxation and Risk-Taking. Quarterly Journal of Economics 58(3), 388-422.

Eaton, J. (1981). Fiscal Policy, Inflation and the Accumulation of Risky Capital. Review of Economic Studies 48(3), 435-445.

Epstein, L. G. and S. E. Zin (1989). Substitution, Risk Aversion, and the Temporal Behavior of Consumption Growth and Asset Returns I: A Theoretical Framework. Econometrica 57(4), 937-969.

Fama, E. E. and K. F. French (2002). The Equity Premium. Journal of Finance 57(2), 637-659.

Gordon, R. H. (1985). Taxation of Corporate Capital Income: Tax Revenue versus Tax Distortions. Quarterly Journal of Economics 100(1), $1-27$.

Guenther, D. A. and M. Willenborg (1999). Capital Gains Tax Rates and the Cost of Capital for Small Business: Evidence from the IPO Market. Journal of Financial Economics 53(3), 385-408.

Hamilton, J. H. (1987). Taxation, Savings, and Portfolio Choice in a Continuous Time Model. Public Finance / Finances Publiques 42(2), 264281.

Hansen, L. P. and R. Jagannathan (1991). Implications of Security Market Data for Models of Dynamic Economies. Journal of Political Economy $99(2), 225-262$.

Hansen, L. P. and K. J. Singleton (1983). Stochastic Consumption, Risk Aversion, and the Temporal Behavior of Asset Returns. Journal of Political Economy 91 (2), 249-265.

Hassett, K. A. and G. E. Metcalf (1999). Investment with Uncertain Tax Policy: Does Random Tax Policy Discourage Investment? Economic Journal 109 (457), 372-393.

Heaton, J. and D. Lucas (1996). Evaluating the Effects of Incomplete Markets on Risk Sharing and Asset Pricing. Journal of Political Economy 104(3), 668-712.

Internal Revenue Service (Ed.) (1954). Statistics of Income. Washington D.C.: U.S. Treasury Department. 
Jorion, P. and W. N. Goetzmann (1999). Global Stock Markets in the Twentieth Century. Journal of Finance 54 (3), 953-980.

Judd, K. L. (1985). Redistributive Taxation in a Simple Perfect Foresight Model. Journal of Public Economics 28(1), 59-83.

Kaplow, L. (1994). Taxation and Risk Taking: A General Equilibrium Perspective. National Tax Journal 47(4), 789-798.

Kocherlakota, N. R. (1996). The Equity Premium: It's Still a Puzzle. Journal of Economic Literature 34(1), 42-71.

Lang, M. H. and D. A. Shackelford (2000). Capitalization of Capital Gains Taxes: Evidence from Stock Price Reactions to the 1997 Rate Reduction. Journal of Public Economics 76(1), 69-85.

Lucas, R. E. (1978). Asset Prices in an Exchange Economy. Econometrica $46(6), 1429-1445$.

Mankiw, G. N. (1986). The Equity Premium and the Concentration of Aggregate Shocks. Journal of Financial Economics 17(1), 211-219.

Mankiw, G. N. and S. P. Zeldes (1991). The Consumption of Stockholders and Non-Stockholders. Journal of Financial Economics 29(1), 97-112.

McGrattan, E. R. and E. C. Prescott (2001). Taxes, Regulations, and Asset Prices. NBER Working Paper 8623.

Mehra, R. and E. C. Prescott (1985). The Equity Premium: A Puzzle. Journal of Monetary Economics 15(2), 145-161.

Mitchell, B. (1983). International Historical Statistics: The Americas and Australasia. Michigan: Gale Research.

Modigliani, F. and M. M. Miller (1958). The Cost of Capital, Corporate Finance, and the Theory of Investment. The American Economic Review $48(3), 261-297$.

Pechman, J. A. (1985). Who Paid the Taxes, 1966-86? Washington D.C.: The Brookings Institution.

Pechman, J. A. (1987). Federal Tax Policy (Fifth ed.). Washington D.C.: Brookings.

Poterba, J. M. (2000). Stock Market Wealth and Consumption. Journal of Economic Perspectives 14 (2), 99-118. 
Rietz, T. A. (1988). The Equity Risk Premium. A Solution. Journal of Monetary Economics 22(1), 117-131.

Shiller, R. J. (1981). Do Stock Prices Move Too Much to be Justified by Subsequent Changes in Dividends? The American Economic Review 71 (3), 421-436.

Sialm, C. (2001). Tax Changes and Asset Returns: An Empirical Investigation. Stanford University, mimeo.

Sinai, T. and J. Gyourko (2000). The Asset Price Incidence of Capital Gains Taxes: Evidence from the Taxpayer Relief Act of 1997 and Publicly-Traded Real Estate Firms. NBER Working Paper 7893.

Slemrod, J. and T. Greimel (1999). Did Steve Forbes Scare the US Municipal Bond Market? Journal of Public Economics 74 (1), 81-96.

Stiglitz, J. E. (1969). The Effects of Income, Wealth, and Capital Gains Taxation on Risk-Taking. Quarterly Journal of Economics 83(2), 263283.

Storesletten, K., C. I. Telmer, and A. Yaron (2001). Asset Pricing with Idiosyncratic Risk and Overlapping Generations. Carnegie Mellon, mimeo.

U.S. Government Printing Office (Ed.) (2000). Economic Report of the President. Washington D.C.

Vissing-Jørgensen, A. (2002). Limited Stock Market Participation and the Elasticity of Intertemporal Substitution. Journal of Political Economy 110(4), 825-853.

Weil, P. (1989). The Equity Premium Puzzle and the Risk-Free Rate Puzzle. Journal of Monetary Economics 24(2), 401-421.

Zodrow, G. R. (1995). Taxation, Uncertainty and the Choice of a Consumption Tax Base. Journal of Public Economics 38(2), 257-265. 


\section{A Data}

\section{A.1 Marginal Tax Rates}

Taxable income was derived for five real income levels after deducting exemptions for a married couple filing jointly with two dependent children from the income levels. The proportion of total deductions relative to the adjusted gross income was assumed to equal the proportion of total deductions in the whole population for each year as reported by the Internal Revenue Service. The marginal income tax brackets and exemptions were determined using the Statistics of Income of the Internal Revenue Service (1954) for the years 1913-1943, Pechman (1987) for the years 1944-1987, and different issues of the Instructions to Form 1040 from the IRS for the remaining years between 1988-1999. The values of the Consumer Price Index from 1913-1957 were taken from Mitchell (1983) and for the other years from the U.S. Government Printing Office (2000). Total deductions as a proportion of adjusted gross income (AGI) were derived from different issues of the Statistics of Income of the IRS.

\section{B Proofs}

\section{B.1 Proof that Price-Dividend Ratios are Positive}

This proof shows that the price-dividend ratios in equations (20) and (21) are positive if $0<\gamma_{i}<1$ for $i \in\{L, H\}$. The numerator of equation (20) $N_{H}$ is positive if $0<\gamma_{i}<1$ for $i \in\{L, H\}$ :

$$
\begin{aligned}
N_{H} & =\gamma_{H}\left[\rho_{H}+\gamma_{L}\left(1-\phi_{H H}-\phi_{L L}\right)\right] \\
& =\gamma_{H}\left[\phi_{H H}+\phi_{H L} \rho_{H L}+\gamma_{L}\left(1-\phi_{H H}-\phi_{L L}\right)\right] \\
& =\gamma_{H}\left[\phi_{H H}\left(1-\gamma_{L}\right)+\phi_{H L} \rho_{H L}+\gamma_{L}\left(1-\phi_{L L}\right)\right]>0 .
\end{aligned}
$$

The denominator $D_{H}$ of equation (20) is positive if $0<\gamma_{i}<1$, because:

$$
\begin{aligned}
1-D_{H} & =\phi_{H H} \gamma_{H}+\phi_{L L} \gamma_{L}+\gamma_{H} \gamma_{L}\left(1-\phi_{H H}-\phi_{L L}\right) \\
& =\gamma_{H}\left[\phi_{H H}+\phi_{H L} \gamma_{L}\right]+\gamma_{L}\left[\phi_{L L}+\phi_{L H} \gamma_{H}\right]-\gamma_{H} \gamma_{L} \\
& \leq \gamma_{H}+\gamma_{L}-\gamma_{H} \gamma_{L}=\gamma_{H}+\left(1-\gamma_{H}\right) \gamma_{L}<1 .
\end{aligned}
$$

Similar operations show that (21) is positive. 


\section{B.2 Proof of Proposition 1}

(i) If $\mu_{L}=\mu_{H}$ and $\sigma_{L}=\sigma_{H}$, then $\gamma_{L}=\gamma_{H}$. In this case only the first product in the numerator differs between equations (20) and (21). $\rho_{H L}=$ $\left[\left(1-\tau_{L}\right) /\left(1-\tau_{H}\right)\right]\left[\left(1-\omega \tau_{L}\right) /\left(1-\omega \tau_{H}\right)\right]^{-\alpha} \cdot \rho_{H L}=1$ if $\alpha=\tilde{\alpha}$ and $\partial \rho_{H L} / \partial \alpha \leq 0$. Thus, $\rho_{H L} \gtreqless 1$ if $\alpha \lesseqgtr \tilde{\alpha}$. Because $\rho_{L H}=1 / \rho_{H L}, \rho_{L H} \lesseqgtr 1$ if $\alpha \lesseqgtr \tilde{\alpha}$. $\rho_{H}=\phi_{H H}+\phi_{H L} \rho_{H L}$ and $\rho_{L}=\phi_{L L}+\phi_{L H} \rho_{L H}$ are simply weighted averages of $\rho_{H L}$ and $\rho_{L H}$ with 1 , respectively. Thus, $\rho_{H} \gtreqless 1 \gtreqless \rho_{L}$ if $\alpha \lesseqgtr \tilde{\alpha}$. $\delta_{H} \gtreqless \delta_{L}$ if $\rho_{H} \gtreqless \rho_{L}$, because the denominators in equations (20) and (21) are positive as proved in Appendix B.1 and because by assumption $0<\gamma_{L}=\gamma_{H}$. Thus, $\delta_{H} \gtreqless \delta_{L}$ if $\alpha \lesseqgtr \tilde{\alpha}$.

(ii) Equations (20) and (21) differ only in the first product of their numerators. The denominators in equations (20) and (21) are positive as proved in Appendix B.1. Therefore $\delta_{H} \gtreqless \delta_{L}$ if $\gamma_{H} \rho_{H} \gtreqless \gamma_{L} \rho_{L}$.

\section{B.3 Proof of Proposition 2}

I show the conditions which are necessary for bond prices to be higher in the high-tax regime. The bond price ratio $\psi^{m}$ with maturity $m>1$ is:

$$
\psi^{m}=\frac{p_{H}^{B, m}}{p_{L}^{B, m}}=f\left(\psi^{m-1}\right)=\frac{\lambda_{H}\left[\phi_{H H} \psi^{m-1}+\phi_{H L} \rho_{H L}\right]}{\lambda_{L}\left[\phi_{L L}+\phi_{L H} \rho_{L H} \psi^{m-1}\right]}
$$

The bond price ratio is a function of its lagged value $\psi^{m}=f\left(\psi^{m-1}\right)$. Its first derivative is:

$$
\frac{d \psi^{m}}{d \psi^{m-1}}=\frac{\lambda_{H} \lambda_{L}\left[\phi_{H H}+\phi_{L L}-1\right]}{\left[\lambda_{L}\left(\phi_{L L}+\phi_{L H} \rho_{L H} \psi^{m-1}\right)\right]^{2}}
$$

Thus, $d \psi^{m} / d \psi^{m-1} \gtreqless 0$ and $d^{2} \psi^{m} / d \psi^{m-1}{ }^{2} \lesseqgtr 0$ if $\phi_{H H}+\phi_{L L} \gtreqless 1 . f$ is increasing and concave if the tax regimes are persistent and decreasing and convex if the tax regimes are transitory. Moreover, $\psi^{m}$ is positive for all maturities $m$.

Figure 8 depicts four different cases, depending on whether tax rates are persistent and depending on the size of the discount factors: In case 1.1 tax regimes are persistent $\left(\phi_{H H}+\phi_{L L}>1\right)$ and the discount factor is higher in the high-tax regime $\left(\lambda_{H} \rho_{H}>\lambda_{L} \rho_{L}\right)$. In the first period, $\psi^{1}=f(1)=$ $\lambda_{H} \rho_{H} / \lambda_{L} \rho_{L}>1$. Because $f(\psi)$ is increasing and concave, $\psi^{2}=f\left(\psi^{1}\right)>\psi^{1}$. The bond price ratio increases monotonically and converges to its steady 
Figure 8: Dynamics of Price Ratio $\psi$

These figures depict the bond price ratios $\psi$ in four different cases according to equation (31). If tax regimes are persistent, then the price ratio $\psi$ converges monotonically to its steady state (Cases 1.1 and 1.2). If tax regimes are transitory, then the price ratio oscillates around its steady state (Cases 2.1 and 2.2). The bond-price ratio $\psi$ is larger than one if $\lambda_{H} \rho_{H}>\lambda_{L} \rho_{L}$ (Cases 1.1 and 2.1) and smaller than one if $\lambda_{H} \rho_{H}<\lambda_{L} \rho_{L}$ (Cases 1.2. and $2.2)$.

Case 1: Persistent Tax Regimes $\left(\phi_{H H}+\phi_{L L}>1\right)$

Case 1.1: $\lambda_{H} \rho_{H}>\lambda_{L} \rho_{L}$

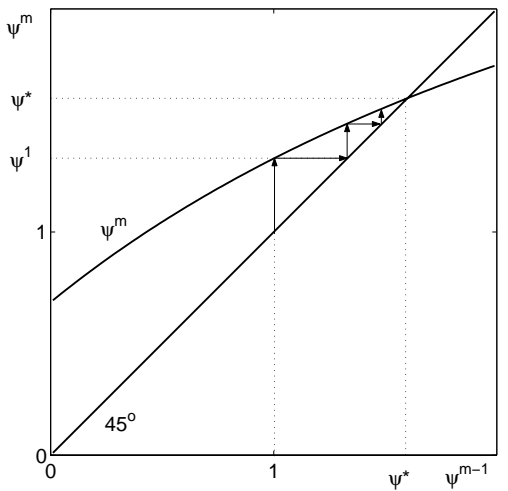

Case 1.2: $\lambda_{H} \rho_{H}<\lambda_{L} \rho_{L}$

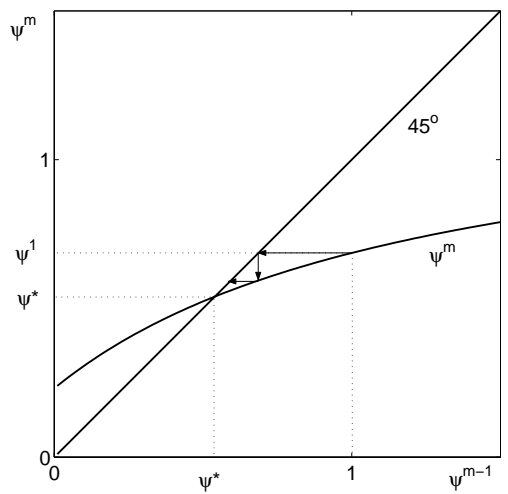

Case 2: Transitory Tax Regimes $\left(\phi_{H H}+\phi_{L L}<1\right)$

Case 2.1: $\lambda_{H} \rho_{H}>\lambda_{L} \rho_{L}$

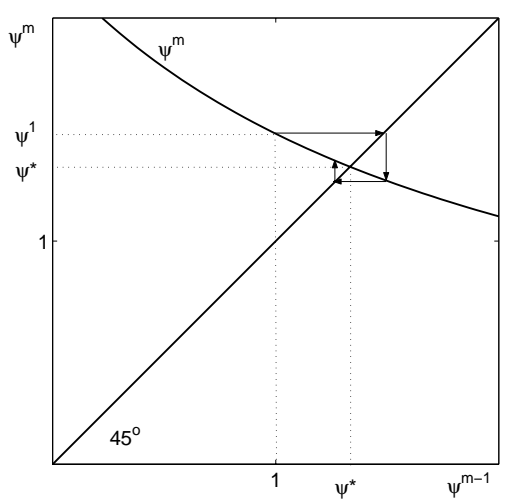

Case 2.2: $\lambda_{H} \rho_{H}<\lambda_{L} \rho_{L}$

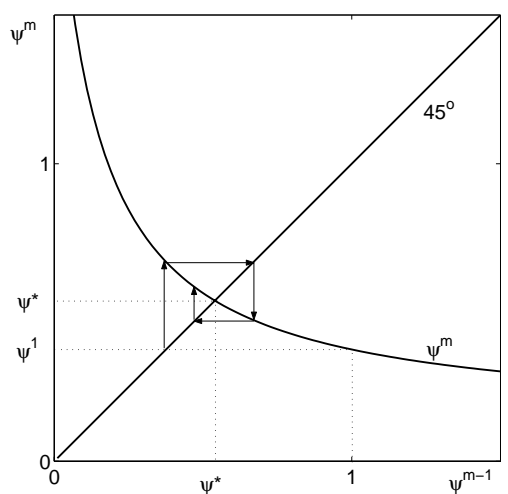


state $\psi *>1$. Thus, $\psi^{m}>1$ for all maturities. In case 1.2 tax regimes are persistent and the discount factor is lower in the high-tax regime. In the first period, $\psi^{1}=f(1)=\lambda_{H} \rho_{H} / \lambda_{L} \rho_{L}<1$. Because $f(\psi)$ is increasing and concave, $\psi^{2}=f\left(\psi^{1}\right)<\psi^{1}$. The bond price ratio decreases monotonically and converges to its steady state $\psi *<1 . \psi^{m}<1$ for all maturities.

This proves that Proposition 2 holds if tax rates are persistent. The following discussion shows that the proposition also holds in cases 2.1 and 2.2. In case 2.1 tax regimes are transitory and the discount factor is higher in the high-tax regime. In the first period, $\psi^{1}=f(1)=\lambda_{H} \rho_{H} / \lambda_{L} \rho_{L}>1$. Because $f(\psi)$ is decreasing and convex, $\psi^{2}=f\left(\psi^{1}\right)<\psi *$. The bond price ratio oscillates around its steady state $\psi *>1$. In case 2.2 tax regimes are transitory and the discount factor is lower in the high-tax regime. In the first period, $\psi^{1}=f(1)=\lambda_{H} \rho_{H} / \lambda_{L} \rho_{L}<1$. Because $f(\psi)$ is decreasing and convex, $\psi^{2}=f\left(\psi^{1}\right)>\psi *$. The bond price ratio oscillates around its steady state $\psi *<1$.

Next, I analyze whether the price ratios converge to the steady-state level $\psi *$. Suppose first, that $\phi_{H H}=\phi_{L L}=0$. In this case, the function $f$ is identical to its inverse $f^{-1}$ :

$$
f(\psi)=f^{-1}(\psi)=\frac{\lambda_{H} \rho_{H L}}{\lambda_{L} \rho_{L H} \psi} .
$$

Thus, the bond ratio $\psi$ follows in this case a cycle of $\psi^{m}=\psi^{1}=$ $\lambda_{H} \rho_{H} / \lambda_{L} \rho_{L}$ if $m$ is odd and $\psi^{m}=\psi^{0}=1$ if $m$ is even. With $\phi_{H H}=\phi_{L L}=0$, the price ratio $\psi$ does not converge to $\psi *$. Proposition 2 still holds in this case because $\psi^{m} \geq 1$ for all $m$ if $\lambda_{H} \rho_{H}>\lambda_{L} \rho_{L}$ and $\psi^{m} \leq 1$ for all $m$ if $\lambda_{H} \rho_{H}<\lambda_{L} \rho_{L}$.

The next sections show that the bond price ratio $\psi^{m}$ converges to $\psi *$ as $m$ goes to $\infty$ as long as either $\phi_{H H}>0$ or $\phi_{L L}>0$. First, I look at the case where $0<\psi^{m}<\psi *$. The price ratio converges to $\psi *$ if $\psi^{m+1}<\psi^{m-1}$ for all possible $m$. Note that both $\psi^{m+1}$ and $\psi^{m-1}$ are larger than $\psi *$ if $\psi^{m}<\psi *$ whenever the price ratios are oscillating around the steady-state value.

The function $f(\psi)$ and its inverse $f^{-1}(\psi)$ are defined as follows:

$$
\begin{aligned}
f(\psi) & =\frac{\lambda_{H}\left(\phi_{H H} \psi+\phi_{H L} \rho_{H L}\right)}{\lambda_{L}\left(\phi_{L L}+\phi_{L H} \rho_{L H} \psi\right)}, \\
f^{-1}(\psi) & =\frac{\lambda_{L} \phi_{L L} \psi-\lambda_{H} \phi_{H L} \rho_{H L}}{\lambda_{H} \phi_{H H}-\lambda_{L} \phi_{L H} \rho_{L H} \psi} .
\end{aligned}
$$


Note that $\psi^{m+1}=f\left(\psi^{m}\right)$ and $\psi^{m-1}=f^{-1}\left(\psi^{m}\right)$ by the definition of the functions $f$ and $f^{-1}$. The price ratio $\psi$ converges to its steady-state level $\psi *$ if $f(\psi)<f^{-1}(\psi)$ for all possible $\psi<\psi *$. Thus, the price ratio converges if:

$$
\frac{\lambda_{H}\left(\phi_{H H} \psi+\phi_{H L} \rho_{H L}\right)}{\lambda_{L}\left(\phi_{L L}+\phi_{L H} \rho_{L H} \psi\right)}<\frac{\lambda_{L} \phi_{L L} \psi-\lambda_{H} \phi_{H L} \rho_{H L}}{\lambda_{H} \phi_{H H}-\lambda_{L} \phi_{L H} \rho_{L H} \psi} .
$$

The function $f$ is decreasing in cases 2.1 and 2.2 and takes its lowest level if $\psi \rightarrow \infty$ :

$$
\lim _{\psi \rightarrow \infty} f(\psi)=\frac{\lambda_{H} \phi_{H H}}{\lambda_{L} \phi_{L H} \rho_{H L}} .
$$

The denominator of the right side of equation (36) is negative, because $\lambda_{H} \phi_{H H}-\lambda_{L} \phi_{L H} \rho_{L H} \psi \leq \lambda_{H} \phi_{H H}-\lambda_{L} \phi_{L H} \rho_{L H}\left(\lambda_{H} \phi_{H H}\right) /\left(\lambda_{L} \phi_{L H} \rho_{H L}\right)=0$.

Simplifying equation (36) gives:

$$
\left[\lambda_{H} \phi_{H H}+\lambda_{L} \phi_{L L}\right] g(\psi)<0,
$$

where:

$$
g(\psi)=\psi^{2}\left(\lambda_{L} \phi_{L H} \rho_{L H}\right)+\psi\left(\lambda_{L} \phi_{L L}-\lambda_{H} \phi_{H H}\right)-\left(\lambda_{H} \phi_{H L} \rho_{H L}\right) .
$$

The first factor of equation (38) is strictly positive as long as either $\phi_{H H}$ or $\phi_{L L}$ is strictly positive. The quadratic equation (39) is exactly identical to the equation that solves for the steady-state price ratio $\psi *$. To derive the equation for the steady state price simply set $\psi *=f(\psi *)$ in equation (34). The solutions to the quadratic equation are:

$$
\psi *_{1,2}=\frac{\lambda_{H} \phi_{H H}-\lambda_{L} \phi_{L L} \pm \sqrt{\left(\lambda_{H} \phi_{H H}-\lambda_{L} \phi_{L L}\right)^{2}+4 \lambda_{L} \lambda_{H} \phi_{H L} \phi_{L H}}}{2 \lambda_{L} \phi_{L H} \rho_{L H}} .
$$

One solution to equation (40) is positive and the other is negative. Since bond prices are always positive we can ignore the negative solution. The quadratic equation (39) is $g(\psi)<0$ if $0 \leq \psi<\psi *$ and $g(\psi)>0$ if $\psi *<\psi<$ $\infty$. Thus, the second factor $g(\psi)$ of equation (38) is negative if $0 \leq \psi<\psi *$. Thus, inequality (36) is satisfied if $0<\psi<\psi *$

Next, I look at the case where $\psi *<\psi^{m}<\infty$. The price ratio $\psi$ converges to its steady-state level $\psi *$ if $f(\psi)>f^{-1}(\psi)$ for all possible $\psi$. Thus, the price ratio converges if:

$$
\frac{\lambda_{H}\left(\phi_{H H} \psi+\phi_{H L} \rho_{H L}\right)}{\lambda_{L}\left(\phi_{L L}+\phi_{L H} \rho_{L H} \psi\right)}>\frac{\lambda_{L} \phi_{L L} \psi-\lambda_{H} \phi_{H L} \rho_{H L}}{\lambda_{H} \phi_{H H}-\lambda_{L} \phi_{L H} \rho_{L H} \psi} .
$$


Following similar steps as for the case where $0 \leq \psi<\psi *$, it can be demonstrated that inequality (41) is satisfied whenever $g(\psi)>0$, which holds if $\psi *<\psi<\infty$.

These arguments show that the bond price ratios $\psi$ converge to the steady-state value $\psi *$ if either $\phi_{H H}>0$ or $\phi_{L L}>0$. In case 2.1, where $\lambda_{H} \rho_{H}>\lambda_{L} \rho_{L}, \psi^{0}=1<\psi^{m}<\psi^{m+2}<\psi *$, where $m$ is even and $\psi^{m}>$ $\psi^{m+2}>\psi *>1$, where $m$ is odd. Thus, $\psi^{m}>1$ for all $m>0$. In case 2.2, where $\lambda_{H} \rho_{H}<\lambda_{L} \rho_{L}, \psi^{0}=1>\psi^{m}>\psi^{m+2}>\psi *$, where $m$ is even and $\psi^{m}<\psi^{m+2}<\psi *<1$, where $m$ is odd. Thus, $\psi^{m}<1$ for all $m>0$. This proves case (i) of the Proposition.

Note that the condition $\lambda_{H} \rho_{H} \gtreqless \lambda_{L} \rho_{L}$ in part (i) simplifies to $\rho_{H} \gtreqless \rho_{L}$ if $\mu_{L}=\mu_{H}$ and $\sigma_{L}=\sigma_{H}$. As shown in the proof to Proposition $1, \rho_{H} \gtreqless \rho_{L}$ if $\alpha \lesseqgtr \tilde{\alpha}$

\section{B.4 Proof of Proposition 3}

This proposition assumes that tax regimes are persistent $\left(\phi_{H H}+\phi_{L L}>1\right)$. I will briefly characterize the term structure if tax regimes are transitory at the end of this section. The expected bond return in the high-tax regime is:

$$
E\left(r_{H}^{B, m}\right)=\frac{\phi_{H H} \psi^{m-1}+\phi_{H L}}{\lambda_{H}\left(\phi_{H H} \psi^{m-1}+\phi_{H L} \rho_{H L}\right)} .
$$

The expected bond return is a function of the bond price ratio: $R_{H}\left(\psi^{m}\right)$, where $\psi^{m}=p_{H}^{B, m} / p_{L}^{B, m}$. The first derivative with respect to $\psi$ is:

$$
\frac{d R_{H}}{d \psi}=\frac{\phi_{H H} \phi_{H L} \lambda_{H}\left(\rho_{H L}-1\right)}{\left[\lambda_{H}\left(\phi_{H H} \psi+\phi_{H L} \rho_{H L}\right)\right]^{2}} .
$$

$d R_{H} / d \psi \gtreqless 0$ if $\rho_{H L} \gtreqless 1$. I demonstrated in Section B.3 that $\psi^{m} \gtreqless$ $\psi^{m-1} \gtreqless 1$ if $\lambda_{H} \rho_{H}-\lambda_{L} \rho_{L} \gtreqless 0$ as long as tax regimes are persistent.

Next I discuss the term structure in four cases: First, if $\lambda_{H} \rho_{H}>\lambda_{L} \rho_{L}$ and $\rho_{H L}>1$, then $\psi^{m}$ increases with $m$ and the expected bond return $R_{H}\left(\psi^{m}\right)$ increases monotonously with the maturity $m$. Second, if $\lambda_{H} \rho_{H}>\lambda_{L} \rho_{L}$ and $\rho_{H L}<1$, then $\psi^{m}$ increases with $m$ and the expected bond return $R_{H}\left(\psi^{m}\right)$ decreases monotonously with the maturity $m$. Third, if $\lambda_{H} \rho_{H}<\lambda_{L} \rho_{L}$ and $\rho_{H L}>1$, then $\psi^{m}$ decreases with $m$ and the expected bond return $R_{H}\left(\psi^{m}\right)$ decreases monotonously with the maturity $m$. Fourth, if $\lambda_{H} \rho_{H}<\lambda_{L} \rho_{L}$ and 
$\rho_{H L}<1$, then $\psi^{m}$ decreases with $m$ and the expected bond return $R_{H}\left(\psi^{m}\right)$ increases monotonously with the maturity $m$. Thus, the bonds with longer maturity have a higher expected return in the high-tax state if $\left(\lambda_{H} \rho_{H}-\right.$ $\left.\lambda_{L} \rho_{L}\right)\left(\rho_{H L}-1\right)>0$. It can also be shown that bonds with longer maturity have a higher expected return in the low-tax state if $\left(\lambda_{L} \rho_{L}-\lambda_{H} \rho_{H}\right)\left(\rho_{L H}-1\right)$. Note that this condition is identical to $\left(\lambda_{H} \rho_{H}-\lambda_{L} \rho_{L}\right)\left(\rho_{H}-1\right)>0$. This proves part (ii) of the Proposition.

In part (i), it is assumed that $\lambda_{H}=\lambda_{L}$. The condition from part (ii) is equivalent to $\left(\rho_{H}-\rho_{L}\right)\left(\rho_{H L}-1\right)>0$. Note that $\rho_{H}=\phi_{H H}+\left(1-\phi_{H H}\right) \rho_{H L}$. Thus, $\rho_{H}$ is between 1 and $\rho_{H L}$ and $\rho_{L}$ is between 1 and $\rho_{L H}$. The sign of $\left(\rho_{H}-\rho_{L}\right)$ is therefore identical to the sign of $\left(\rho_{H L}-1\right)$. This implies that $\left(\lambda_{H} \rho_{H}-\lambda_{L} \rho_{L}\right)\left(\rho_{H L}-1\right)$ is always positive. This concludes the proof.

Next, I characterize the expected returns of bonds with maturity $m$ if tax regimes are transitory. $d R_{H} / d \psi \gtreqless 0$ holds again if $\rho_{H L} \gtreqless 1$. With transitory regimes $\psi^{m} \gtreqless \psi^{m-2} \gtreqless 0$ and $\psi^{m} \gtreqless \psi * \gtreqless \psi^{m-1} \gtreqless 0$ if $\lambda_{H} \rho_{H}-\lambda_{L} \rho_{L} \gtreqless 0$. Thus, the bond price ratio fluctuates around its steady state value.

The term structure has the following shape in the different cases: First, if $\lambda_{H} \rho_{H}>\lambda_{L} \rho_{L}$, then $\psi^{m}$ increases with $m$ if $m$ is odd and decreases if even. Second, if $\lambda_{H} \rho_{H}<\lambda_{L} \rho_{L}$, then $\psi^{m}$ decreases with $m$ if $m$ is odd and increases if even. The expected bond return $R_{H}\left(\psi^{m}\right)$ oscillates around its steady state and converges towards the steady state if either $\phi_{H H}>0$ or $\phi_{L L}>0$. If $\phi_{H H}=\phi_{L L}=0$, then the bond price ratio $\psi$ and the bond return follow a stable cycle.

\section{B.5 Proof of Proposition 4}

The following proof holds in the high-tax state. The proof for the low-tax state is similar. The return of equity in the high-tax state equals:

$$
\begin{aligned}
E\left(r_{H}^{S}\right) & =\xi_{H}\left(\phi_{H H} \frac{1+\delta_{H}}{\delta_{H}}+\phi_{H L} \frac{1+\delta_{L}}{\delta_{H}}\right) \\
& =\xi_{H} \frac{1-\phi_{H H} \gamma_{H}-\phi_{L L} \gamma_{L}+\phi_{H H} \gamma_{H} \rho_{H}+\phi_{H L} \gamma_{L} \rho_{L}}{\gamma_{H}\left[\rho_{H}+\gamma_{L}\left(1-\phi_{H H}-\phi_{L L}\right)\right]} .
\end{aligned}
$$

Plugging the return of the risk-free asset with a maturity of one year during the high-tax-state into equation (44) and simplifying gives the following equation:

$$
E_{t}\left(r_{H}^{S}\right)=r_{H}^{B, 1} \frac{\lambda_{H} \xi_{H}}{\gamma_{H}}\left(1+v_{H}\right)
$$


where:

$$
v_{H}=\gamma_{H} \frac{\phi_{H H}\left(1-\rho_{H}\right)\left(\frac{\gamma_{L}}{\gamma_{H}} \rho_{L}-\rho_{H}\right)}{\phi_{H H}\left(1-\gamma_{L}\right)+\phi_{H L} \rho_{H L}+\gamma_{L} \phi_{L H}} .
$$

The one-period interest rate $r_{H}^{B, 1}=1 /\left(\lambda_{H} \rho_{H}\right)>0$ is defined as the gross return and is therefore always strictly positive. The second factor $\left(\lambda_{H} \xi_{H} / \gamma_{H}=\exp \left(\alpha \sigma_{H}^{2}\right) \geq 1\right.$, because $\left.\alpha \geq 0\right)$ results from the uncertainty of dividend payments. The third factor $1+v_{H}$ results from tax rate changes. This factor equals 1 in an environment without tax rate changes (i.e., $\phi_{H H}=$ $\phi_{L L}=1$ or $\tau_{H}=\tau_{L}$ ), because $\rho_{H}=\rho_{L}=1$.

The premium due to dividend uncertainty $\pi_{H}^{D}$ is positive:

$$
\pi_{H}^{D}=r_{H}^{B, 1} \frac{\lambda_{H} \xi_{H}}{\gamma_{H}}-r_{H}^{B, 1}=\frac{\exp \left(\alpha \sigma_{H}^{2}\right)-1}{\lambda_{H} \rho_{H}} \geq 0
$$

The premium due to tax uncertainty $\pi_{H}^{T}$ is:

$$
\pi_{H}^{T}=r_{H}^{B, 1} \frac{\lambda_{H} \xi_{H}}{\gamma_{H}} v_{H}=\frac{\exp \left(\alpha \sigma_{H}^{2}\right) v_{H}}{\lambda_{H} \rho_{H}}
$$

The sign of $\pi_{H}^{T}$ is identical to the sign of $v_{H}$. The factor $v_{H}$ is negative if $\left(\rho_{L} \gamma_{L}-\rho_{H} \gamma_{H}\right)\left(1-\rho_{H}\right)<0$. The tax premium $\pi_{i}^{T}$ is negative if $\rho_{H} \gamma_{H}<\rho_{L} \gamma_{L}$ whenever $\alpha \leq \tilde{\alpha}$ and if $\rho_{H} \gamma_{H}>\rho_{L} \gamma_{L}$ whenever $\alpha>\tilde{\alpha}$, because $\alpha \leq \tilde{\alpha}$ implies that $\rho_{H} \geq 1$ and $\alpha>\tilde{\alpha}$ implies that $\rho_{H}<1$.

Note that the condition $\left(\rho_{L} \gamma_{L}-\rho_{H} \gamma_{H}\right)\left(1-\rho_{H}\right)<0$ is equivalent to the condition $\left(\rho_{H} \gamma_{H}-\rho_{L} \gamma_{L}\right)\left(1-\rho_{L}\right)<0$, because if $\rho_{H} \lesseqgtr 1$ then $\rho_{L} \gtreqless 1$.

If $\mu_{L}=\mu_{H}$ and $\sigma_{L}=\sigma_{H}$, then $\gamma_{L}=\gamma_{H}$ and $v_{H}$ simplifies to:

$$
v_{H}=\gamma_{H} \frac{\phi_{H H}\left(1-\rho_{H}\right)\left(\rho_{L}-\rho_{H}\right)}{\phi_{H H}\left(1-\gamma_{L}\right)+\phi_{H L} \rho_{H L}+\gamma_{L} \phi_{L H}} .
$$

This term is always positive since the sign of $\left(1-\rho_{H}\right)$ is identical to the sign of $\left(\rho_{L}-\rho_{H}\right)$, because 1 lies between $\rho_{L}$ and $\rho_{H}$. 